LAWRENCE LIVERMORE NATIONAL LABORATORY
NAFEMS Finite Element Benchmarks for MDG Code Verification

R.M. Ferencz

R. Greer

December 31, 2003 


\section{Disclaimer}

This document was prepared as an account of work sponsored by an agency of the United States Government. Neither the United States Government nor the University of California nor any of their employees, makes any warranty, express or implied, or assumes any legal liability or responsibility for the accuracy, completeness, or usefulness of any information, apparatus, product, or process disclosed, or represents that its use would not infringe privately owned rights. Reference herein to any specific commercial product, process, or service by trade name, trademark, manufacturer, or otherwise, does not necessarily constitute or imply its endorsement, recommendation, or favoring by the United States Government or the University of California. The views and opinions of authors expressed herein do not necessarily state or reflect those of the United States Government or the University of California, and shall not be used for advertising or product endorsement purposes.

This work was performed under the auspices of the U.S. Department of Energy by University of California, Lawrence Livermore National Laboratory under Contract W-7405-Eng-48. 


\title{
NAFEMS Finite Element Benchmarks for MDG Code Verification
}

\author{
Robert M. Ferencz \\ Ryan Greer, Summer Scholar \\ Methods Development Group \\ Defense Technologies Engineering Division
}

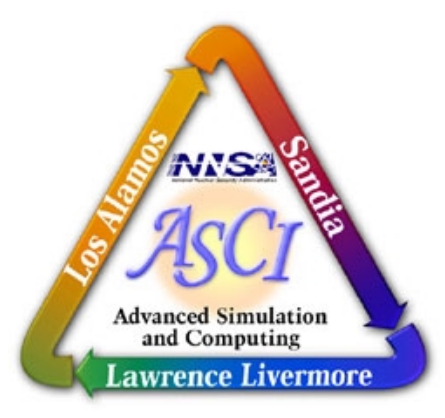

December 31, 2003 


\section{Introduction}

NAFEMS was originally founded at the United Kingdom's National Engineering Laboratory as the National Agency for Finite Element Methods and Standards. It was subsequently privatized as the not-for-profit organization NAFEMS, Ltd., but retains its mission "To promote the safe and reliable use of finite element and related technology". That mission has been pursued in part by sponsoring a series of studies that published benchmarked deemed suitable to assess the basic accuracy of engineering simulation tools. The early studies focused on FEA for linear solid and structural mechanics and then extended to nonlinear solid mechanics, eventually including contact. These benchmarks are complemented by educational materials concerning analysis technologies and approaches. More recently NAFEMS is expanding to consider thermal-fluid problems. Further information is available at wWw.nafems.org.

Essentially all major commercial firms selling FEA for solid mechanics are members of NAFEMS and it seemed clear that Methods Development Group should leverage from this information resource, too. In 2002, W Program ASCI funding purchased a three-year membership in NAFEMS. In the summer of 2003 the first author hosted a summer graduate student to begin modeling some of the benchmark problems. We concentrated on NIKE3D, as the benchmarks are most typically problems most naturally run with implicit FEA. Also, this was viewed as a natural path to generate verification problems that could be subsequently incorporated into the Diablo code's test suite.

This report documents and archives our initial efforts. The intent is that this will be a "living document" that can be expanded as further benchmarks are generated, run, interpreted and documented. To this end each benchmark, or related grouping, is localized in its own section with its own pagination. Authorship (test engineers) will be listed section by section.

\section{Problems}

- Plane Strain Rigid Punch (NL5A/NL5B)

- Cyclic Thermal Loading of Two-Bar Assembly (NL3/NL2A)

- Thermal Ratcheting of Uniform Beam (NL4) 


\title{
Plane Strain Rigid Punch
}

\author{
NAFEMS Benchmarks NL5A and NL5B \\ Ryan Greer and Robert Ferencz \\ August and November 2003
}

\section{Introduction}

A rigid punch is pressed into a finite plate causing a plastic zone to grow through the thickness of the plate. Total punch load, a normal stress component and the effective plastic strain at a material point directly below the edge of the punch are analyzed. NIKE3D solutions are compared to the results of NAFEMS benchmarks NL5B and NL5A, shown on page 13 and 14, respectively. Geometrically identical, the first benchmark exercises strain hardening, while NL5B exercises perfect plasticity.

\section{Definition and Approach}

The punch is assumed rigid and the contact frictionless, allowing the punch to be simulated with a displacement-controlled boundary condition over the plate's nodes in "contact" with the punch. The displacement control is 0.01 units per step and is applied over 24 steps, giving a final deflection of 0.24 units. The plate's material was modeled with NIKE3D's isothermal elastic-plastic Model 3.

The plate is meshed in the $x$ - $y$ plane with $x$ displacements suppressed on the centerline symmetry face. The $z$ displacements are suppressed on both transverse faces creating plane strain conditions. Using half-symmetry the plate is 200 units wide by 160 units thick, and the punch is 80 units wide. The NAFEMS solution used 2D 8-noded quadratic elements, so it was not possible to employ an identical mesh. The NIKE3D mesh was defined with a single layer of 8-node linear bricks, 5 units deep in the transverse direction. For comparison purposes one mesh with the same number of elements and another with nearly the same number of nodes as the NAFEMS mesh were created. The mesh density with equal elements will be referred to as the $n=1$ mesh and consequently for each uniform doubling of the lineal in-plane density of elements we will increase the mesh number by one. So the mesh with approximately equal nodes is labeled $n=2$. Meshes corresponding to $n=3,4,5$ and 6 were also created.

For both benchmarks, results are presented for the vertical normal stress $\sigma_{y y}$ as a function of applied deflection at the material point originally located 20 units directly below the edge of the punch. Following the NAFEMS documentation, this location of concern will be referred to as Point A. A typical finite element method would not directly compute stress at a nodal location. The NAFEMS data are extrapolations to that point using the incident element to the upper-left. For NIKE3D the choice was made to rely upon data most conveniently available to an analyst. Thus the average response for the four surrounding elements, taken from Griz post-processing histories, is used for this benchmark comparison. The Griz results for each element are themselves the average of 
all quadrature points in an element. In some instances we plot the four element averages and their combined average to illustrate the spatial convergence of solutions.

In keeping with our strategy of employing common analyst practice, all simulations were run with NIKE3D's default convergence tolerance. Final executions were made with version 3.4.0 dated September 26, 2003.

\section{Results for NL5A}

Total vertical load per unit depth on the punch is a coarse, aggregate measure that we would expect to quickly agree with the reference solution. Figure 1 confirms this, where all but the coarsest mesh appears to lie upon the reference solution. The NIKE3D results are derived by summing all printed reaction forces, multiplying by 2.0 to account for symmetry, and then dividing by 5.0 to scale to a unit transverse depth. The plot of relative percentage difference (NIKE3D to NAFEMS) in Figure 2 shows a monotonic progression with mesh density. Broadly speaking, the distance between each pair of curves is half that of the preceding pair, which is indicative of the first-order convergence of stress or force expected with this element technology. The best match with the NAFEMS data, within $-0.13 \%$, is achieved for $\mathrm{n}=4$, i.e., 8 × 8 linear ("B-bar") elements in place of each quadratic element of the reference. This is a nice illustration of the power of higher-order interpolation when it is an appropriate technology.

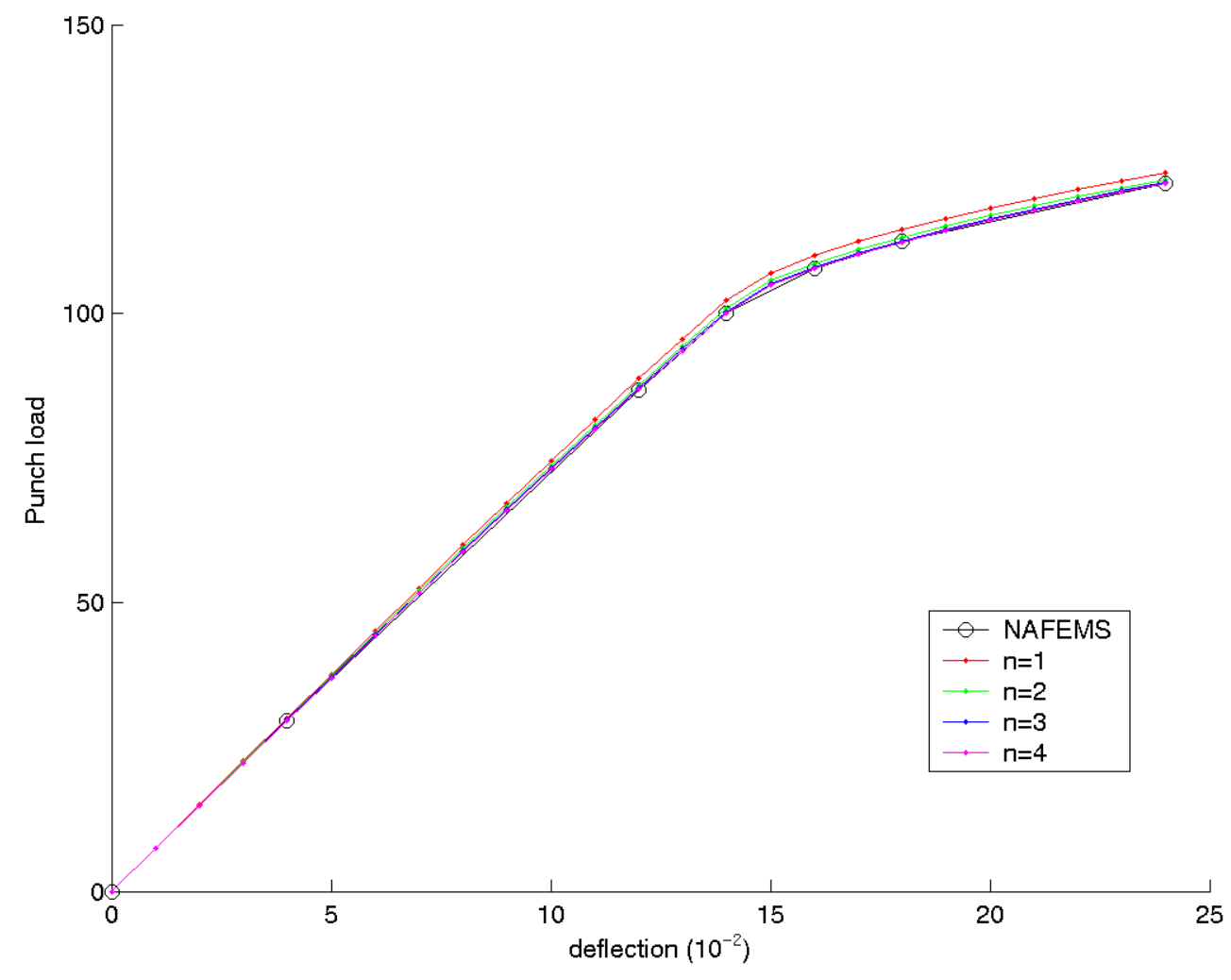

Figure 1 - NAFEMS reference solution NL5A and NIKE3D results for vertical punch load as function of punch deflection. 


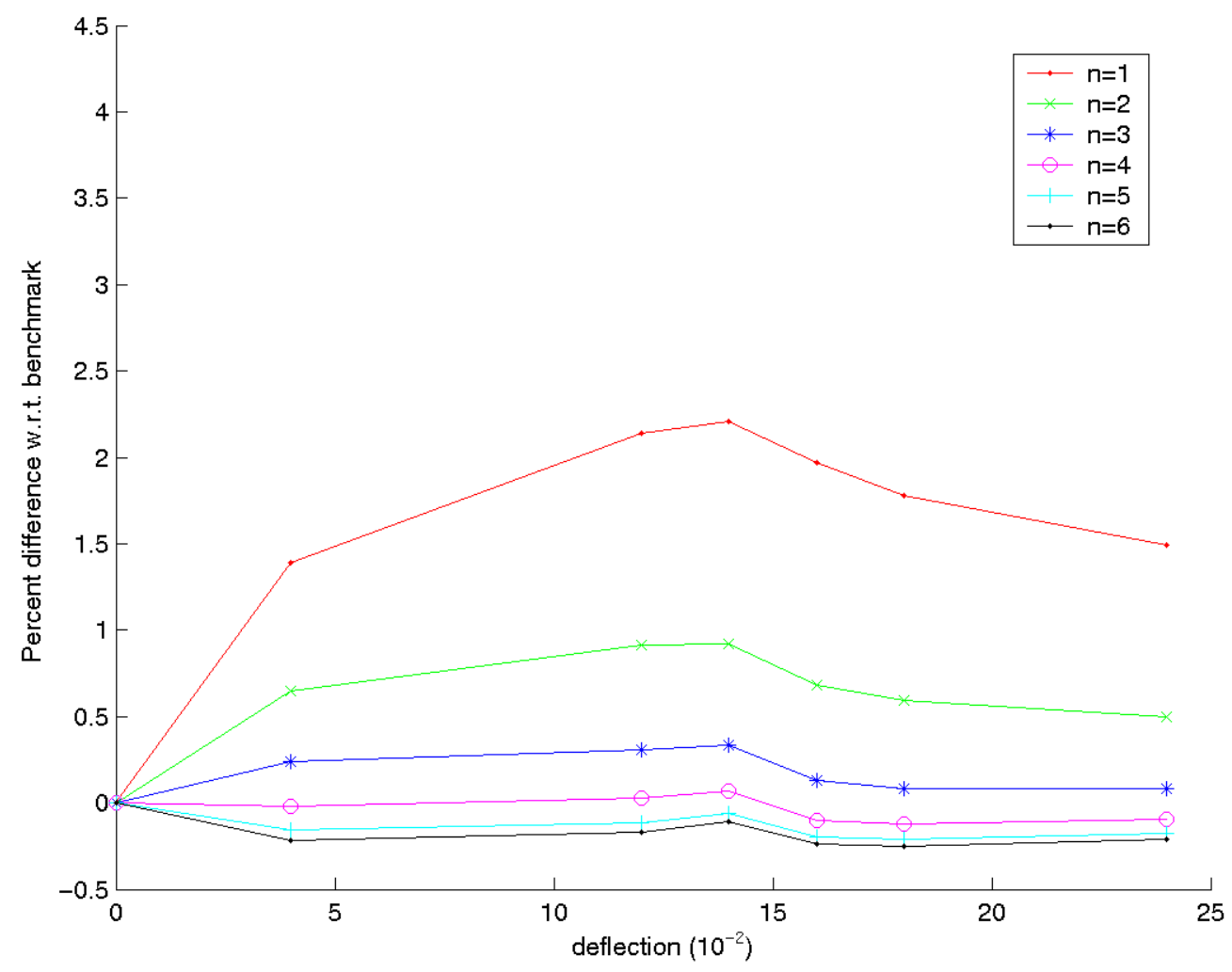

Figure 2 - Percent relative difference between NIKE3D results and NAFEMS reference solution NL5A for vertical punch load as a function of punch deflection.

Tables A1-A6 in Appendix A compare the vertical normal stress $\sigma_{y y}$ from the NIKE3D solutions to the reference solution provided for point $\mathrm{A}$. We isolate the voluminous data to that appendix and provide just a summary here in Table 1. Comparisons are provided both for the single stress value at the final, maximum punch displacement, plus an RMS average for the datum using all the tabulated NAFEMS results. The trends are consistent with the results for the total load shown in Figure 2. The finite element model is slightly stiff, so the total load converges from above, while because the deformations are slightly reduced the stress converges from below. Note that the RMS difference from the NAFEMS result is smallest $(0.49 \%)$ for the $\mathrm{n}=4$ mesh, again consistent with Figure 2. Without further data from NAFEMS, we are unable to assess how converged are these quadratic element results we compare against, but our data suggest the benchmark could have benefited from further refinement. 


\begin{tabular}{|c|c|c|}
\cline { 2 - 3 } \multicolumn{1}{c|}{} & \multicolumn{2}{c|}{ Normal Stress } \\
\hline Mesh Density & Difference at final state \% & RMS Average difference \% \\
\hline 1 & -12.60 & 13.60 \\
\hline 2 & -5.61 & 6.57 \\
\hline 3 & -2.11 & 2.23 \\
\hline 4 & -0.31 & 0.49 \\
\hline 5 & 0.15 & 0.77 \\
\hline 6 & 0.48 & 1.06 \\
\hline
\end{tabular}

Table 1 - NIKE3D-to-NAFEMS comparison of normal stress $\sigma_{\mathrm{yy}}$ at point A for the maximum punch displacement and also the RMS average difference with respect to all tabulated displacements for problem NL5A.

Figures 3 and 4 are included to provide a qualitative impression of the spatial convergence of the six meshes examined. In Figure 3, the normal stress $\sigma_{y y}$ for each element surrounding point $\mathrm{A}$ and the average of these four elements are plotted for each mesh density. The element "numbers" given in the legends are not the mesh element numbers, as these vary for each mesh density. Rather, element number 1 refers to the element to the upper left of Point A, element 2 refers to the upper right, element 3 refers to the bottom right, and element 4 refers to the bottom left, i.e., a clockwise progression around Point $A$. The plot for the $n=4$ mesh already shows about a variance of $+/$ - five percent about the average. The results for the $n=6$ case show exceedingly tight grouping and clearly exceeds the level of mesh refinement that we would achieve in a practical calculation. The motivation for including cases $n=5$ and 6 will not be clear until the discussion of NL5B. Figure 4 provides the effective plastic strain response for the identical groupings of elements. It is interesting to note that for the coarsest mesh the yielding of the elements is spread over the interval $[0.11,0.15]$ of punch displacement. In contrast, with the highly refined meshes of $n=5$ and 6 , all the elements adjoining Point $A$ go plastic simultaneously at a punch displacement of 0.14 . It most be admitted that some of this perceived "smearing" of the initial yielding is accentuated by our use of the element-averaged results plotted by Griz.

As a final check, we wanted to ensure that the choice of kinematic description did not significantly impact the comparison with NAFEMS. Therefore we reran mesh $n=4$ using the linear, small deformation kinematics option of NIKE3D. We believe the general, finite deformation kinematics of NIKE3D's default methodology is more accurate, but in cases of linear elasticity or other small-deformation phenomenon, it can be important to override this default to match analytic solutions. The data in Table A7, when compared to Table A4, shows the solutions to be qualitatively quite similar; on an RMS basis the linear kinematic case $(0.55 \%)$ is slightly less in agreement with NAFEMS than the finite deformation result $(0.49 \%)$. 

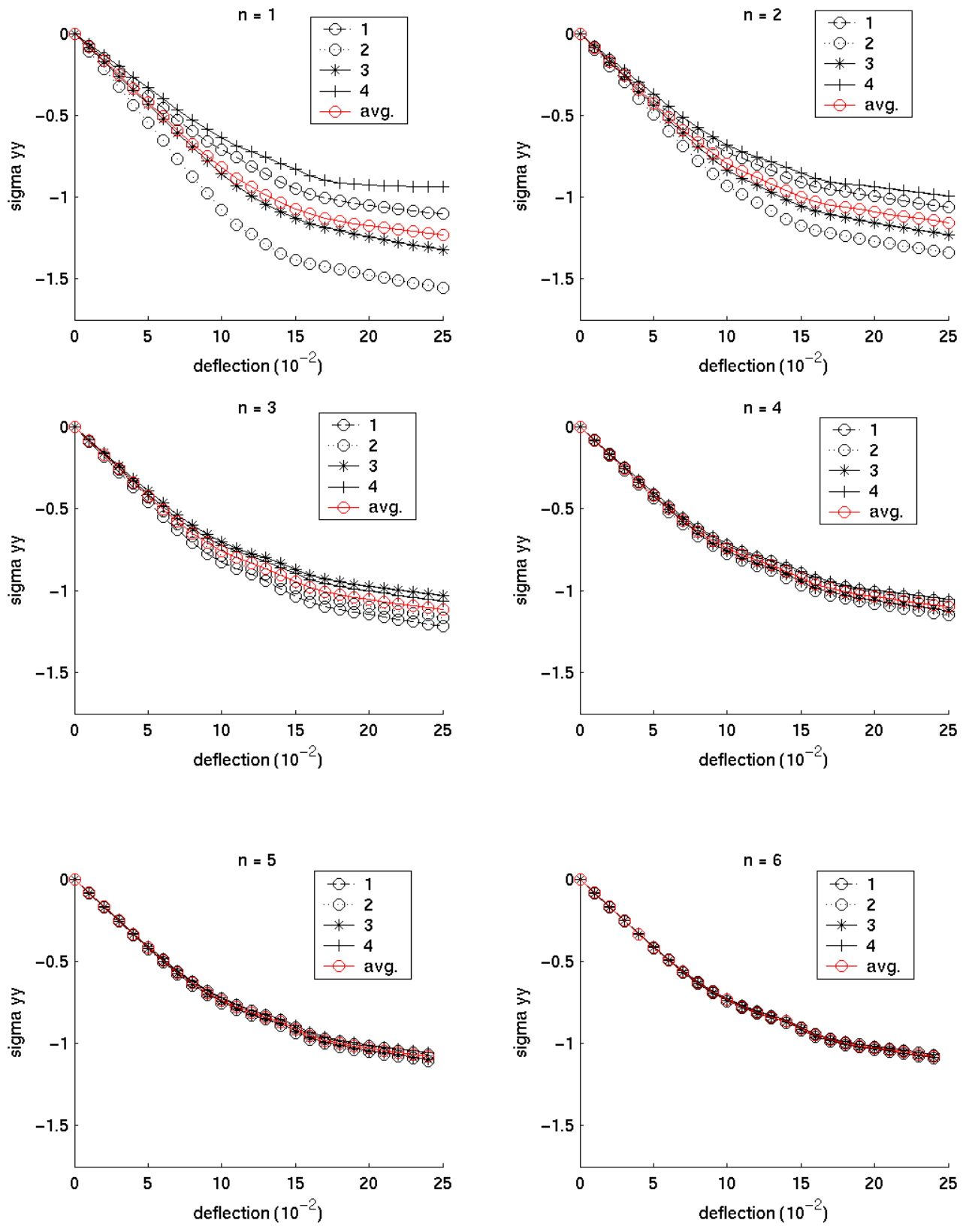

Figure 3 - Normal stress $\sigma_{\mathrm{yy}}$ for the four elements surrounding Point A and their respective average for successive mesh densities computed with NIKE3D for problem NL5A. 

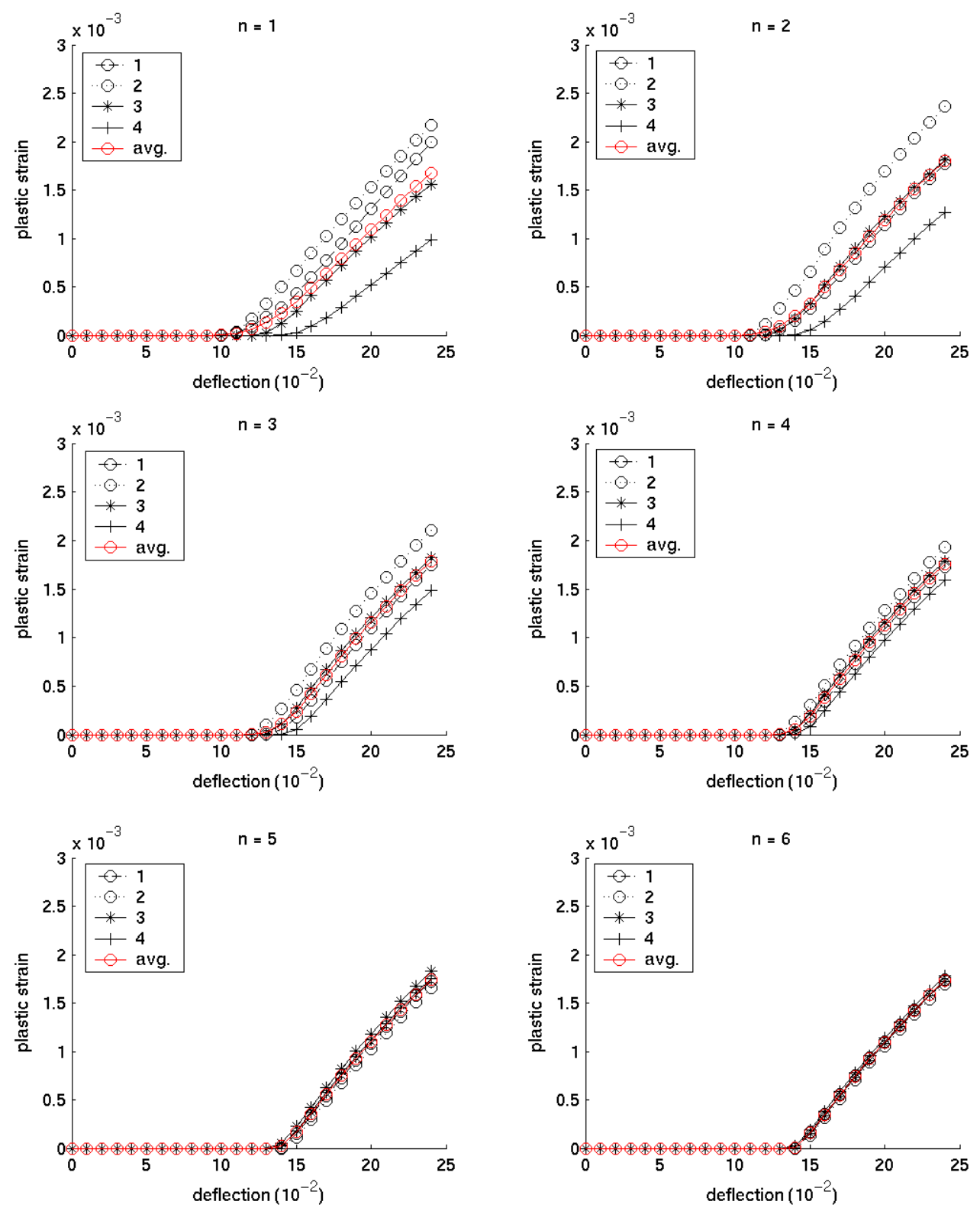

Figure 4 - Effective plastic strain of the four elements surrounding Point A and their respective average for successive mesh densities computed with NIKE3D for problem NL5A. 


\section{Results for NL5B}

Benchmark NL5B utilizes the identical geometry and loading as NL5A, but exercises perfect plasticity. Figures 5 and 6 exhibit a greater spread in the total vertical load per unit depth on the punch than was seen in the hardening case (cf. Figures 1 and 2). The best match with the NAFEMS data, within $-0.043 \%$, is again achieved for the $\mathrm{n}=4$ mesh density. Likewise, the trend in the curves of Figure 6 is consistent with the first-order convergence expected for the force.

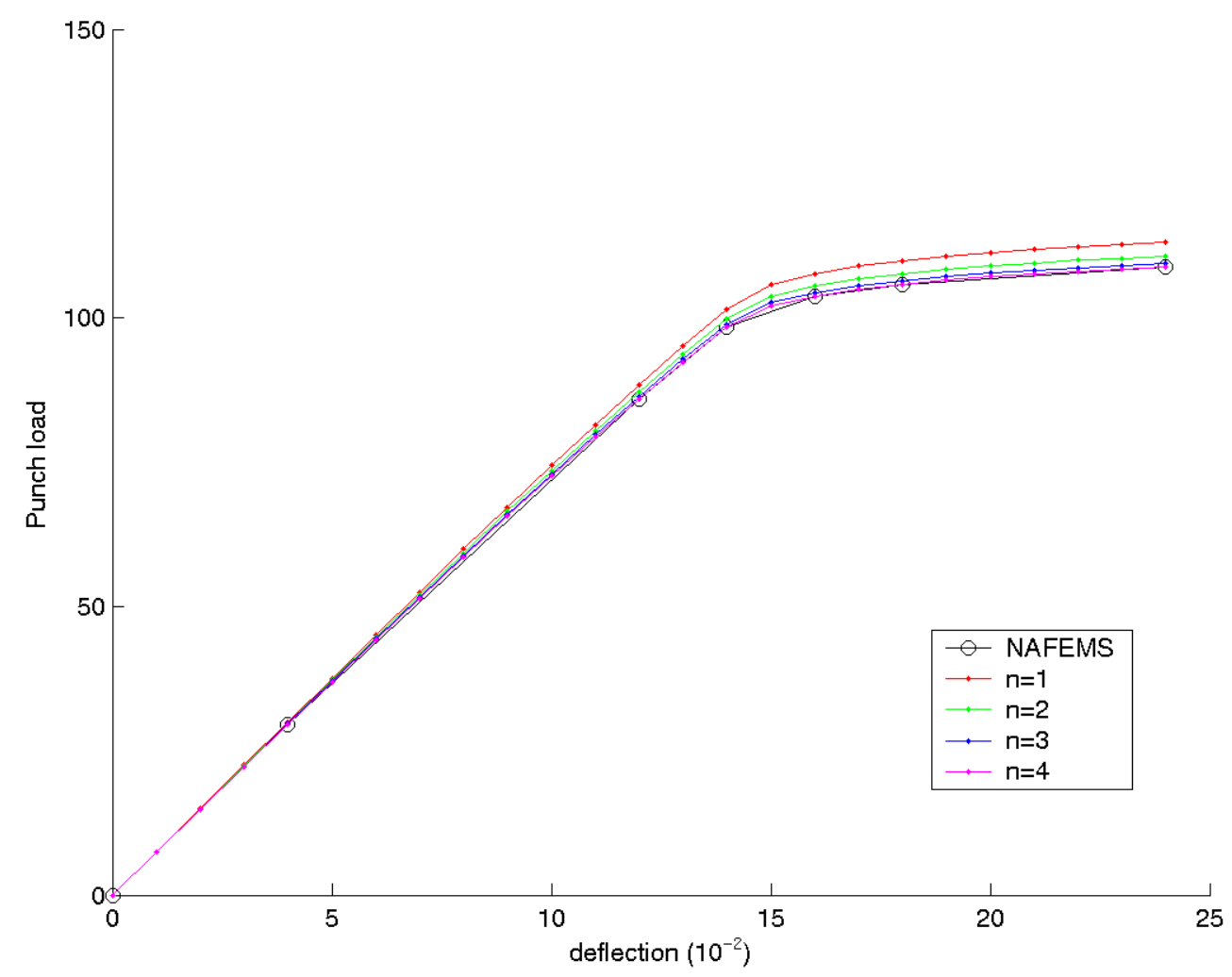

Figure 5 - NAFEMS reference solution NL5B and NIKE3D results for vertical punch load as function of punch deflection.

Tables B1-B6 in Appendix B compare the vertical normal stress $\sigma_{\mathrm{yy}}$ from the NIKE3D solutions to the reference solution provided for Point A. Table 2 lists a convenient summary in the same format as Table 1 previously. In this case the spread in the RMS average is more than double that seen for NL5A, and the minimum RMS difference from the NAFEMS result (still $3.47 \%$ ) is for the $\mathrm{n}=3$ mesh. It was this trend, with the $\mathrm{n}=4$ result substantially further from the benchmark result than for $n=3$, that originally motivated us to examine the $\mathrm{n}=5$ and 6 mesh densities. 


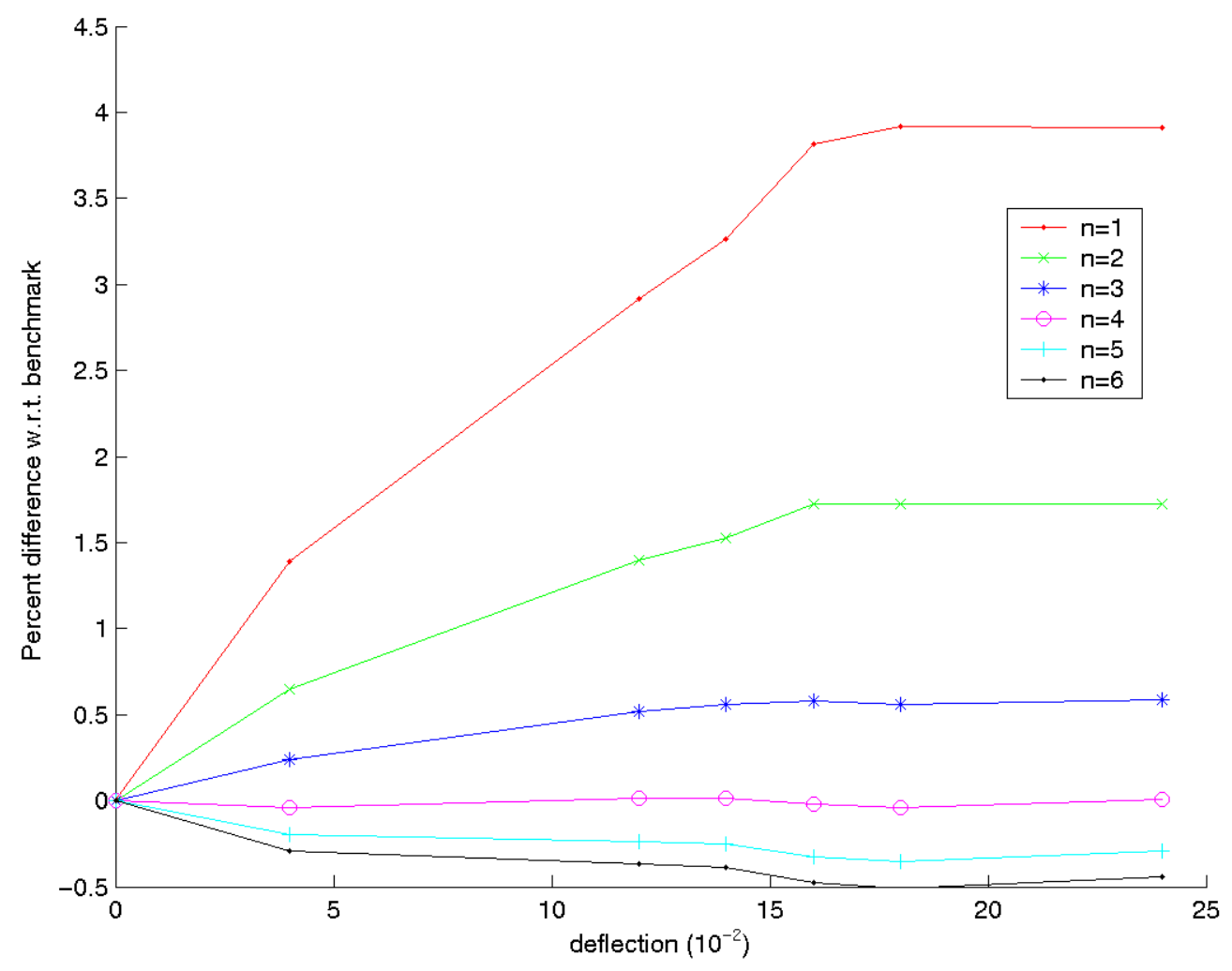

Figure 6 - Percent relative difference between NIKE3D results and NAFEMS reference solution NL5B for vertical punch load as a function of punch deflection.

\begin{tabular}{|c|c|c|}
\cline { 2 - 3 } \multicolumn{1}{c|}{} & \multicolumn{2}{c|}{ Normal Stress } \\
\hline Mesh Density & Difference at final state \% & RMS Average difference \% \\
\hline 1 & -10.52 & 22.26 \\
\hline 2 & -0.01 & 11.59 \\
\hline 3 & 6.45 & 3.47 \\
\hline 4 & 11.25 & 6.41 \\
\hline 5 & 13.33 & 7.66 \\
\hline 6 & 10.03 & 8.17 \\
\hline
\end{tabular}

Table 2 - NIKE3D-to-NAFEMS comparison of normal stress $\sigma_{\mathrm{yy}}$ at Point A for the maximum punch displacement and also the RMS average difference with respect to all tabulated displacements for problem NL5B. 
Figures 7 and 8 present normal stress $\sigma_{\mathrm{yy}}$ and effective plastic strain data for Point A using the same conventions as Figures 3 and 4 did for NL5A. The stress data in Figure 7 are rather unexceptional, showing the expected trend toward spatial convergence with increasing mesh density. However, Figure 8 shows a marked decrease in the plastic strain going from mesh density $n=3$ to 4 , and subsequently the plastic strains are zero for the two highest mesh densities.
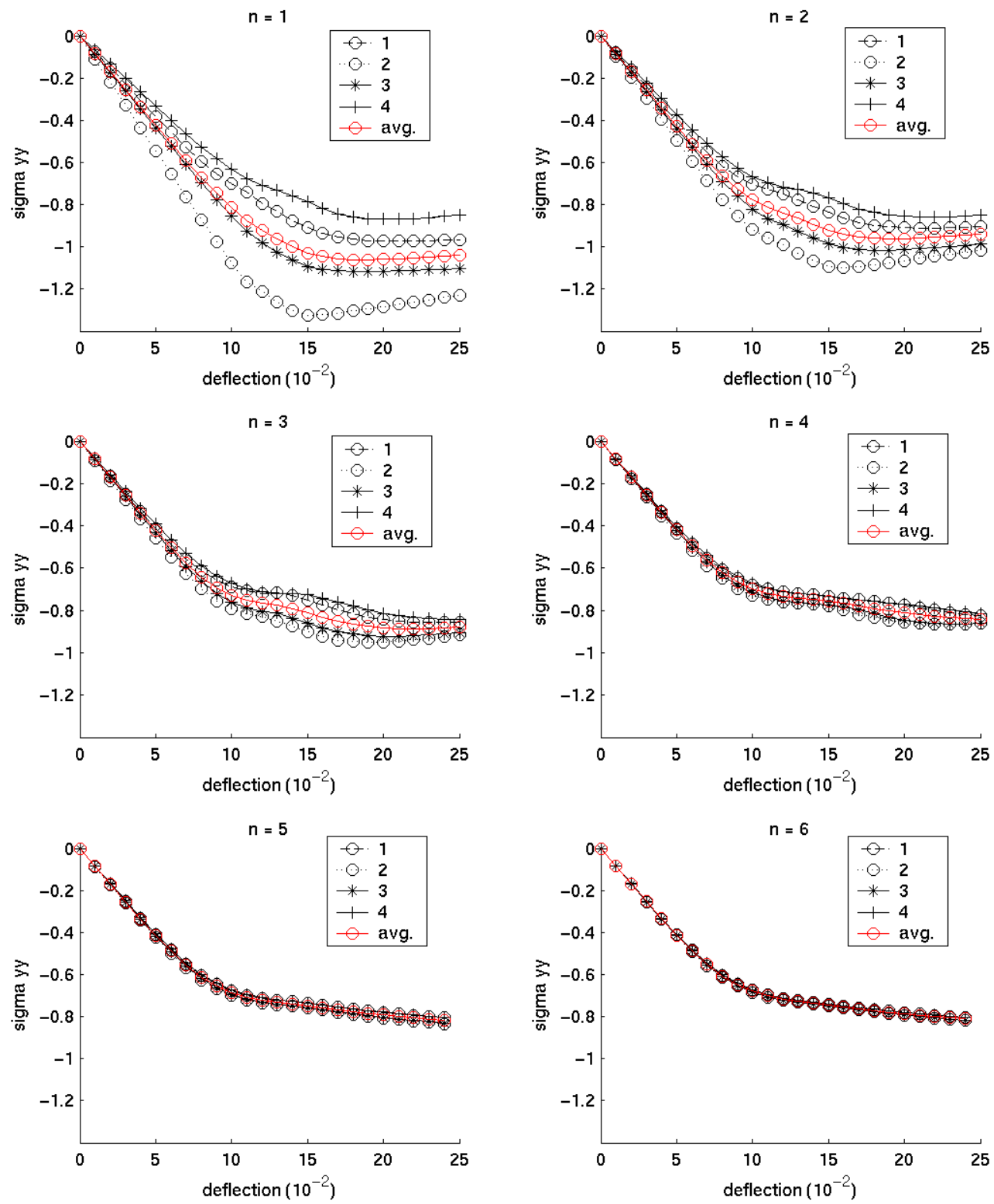

Figure 7 - Normal stress $\sigma_{\text {yy }}$ for the four elements surrounding Point A and their respective average for successive mesh densities computed with NIKE3D for problem NL5B. 

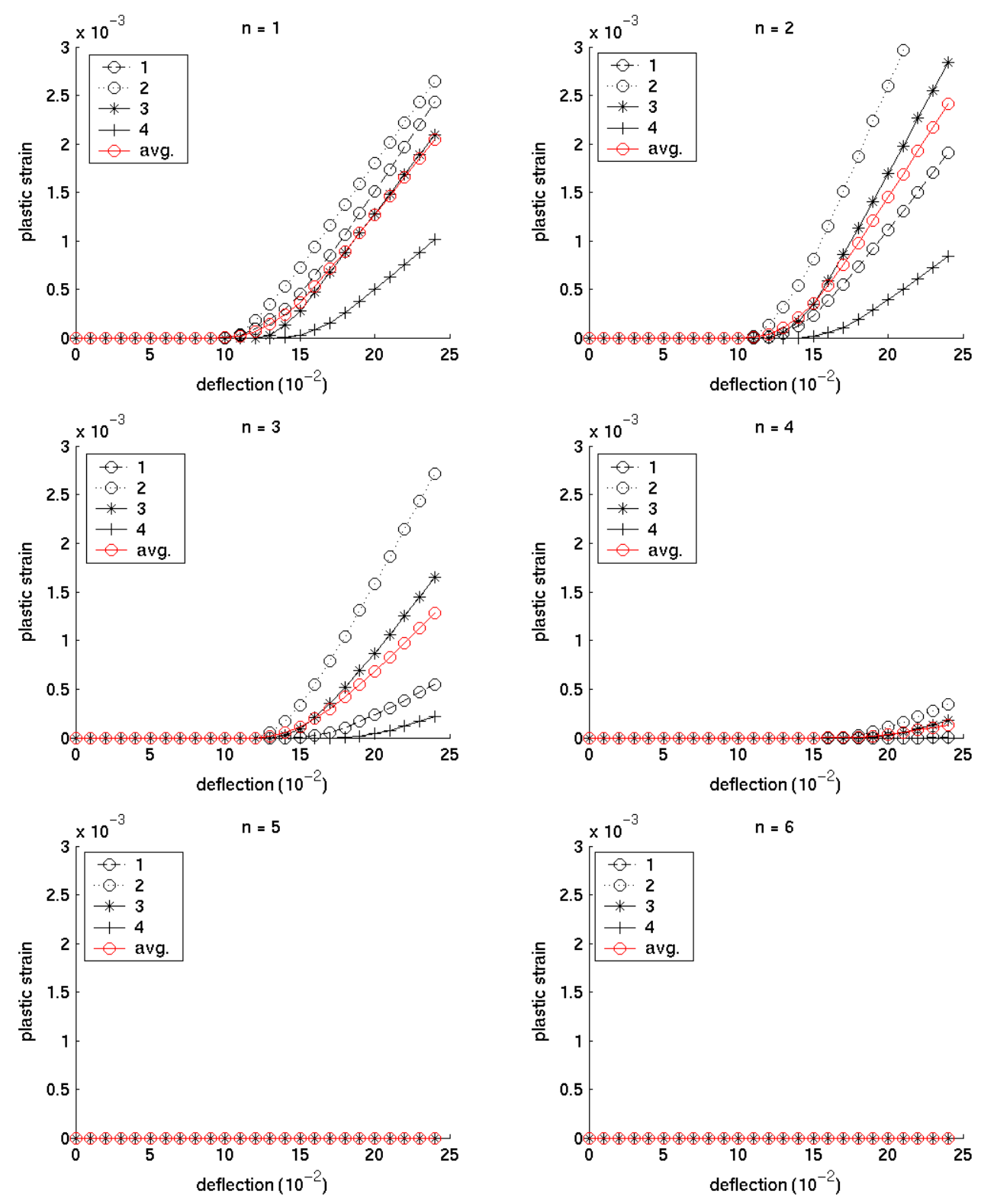

Figure 8 - Effective plastic strain of the four elements surrounding Point A and their respective average for successive mesh densities computed with NIKE3D for problem NL5B.

Figure 9 presents a series of plastic strain contour plots for NL5A and NL5B for the finest mesh $(640 \times 512=327,680$ elements $)$. The strain hardening case has broader, more gradual, contours. The concentrated zones of yielding in the perfect plasticity case reminds one of the efficacy of the early slip line theory of plasticity used to investigate such problems. With sufficient resolution the yield front does not extend to Point A initially located 20 units directly below the edge of the punch, leading to the substantial disagreement between the NAFEMS and refined NIKE3D results. 
NL5A
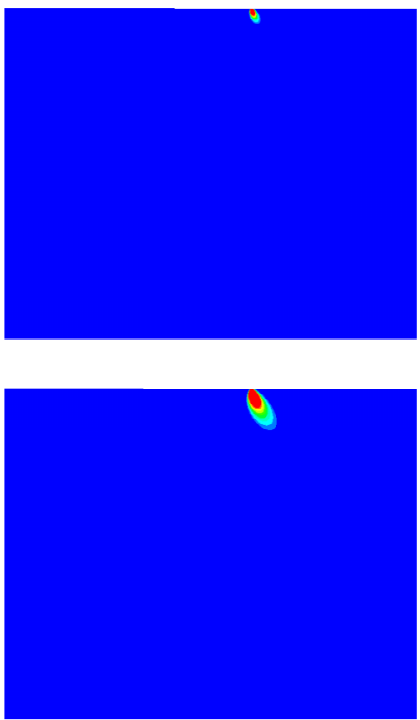

$d=0.08$

$d=0.12$
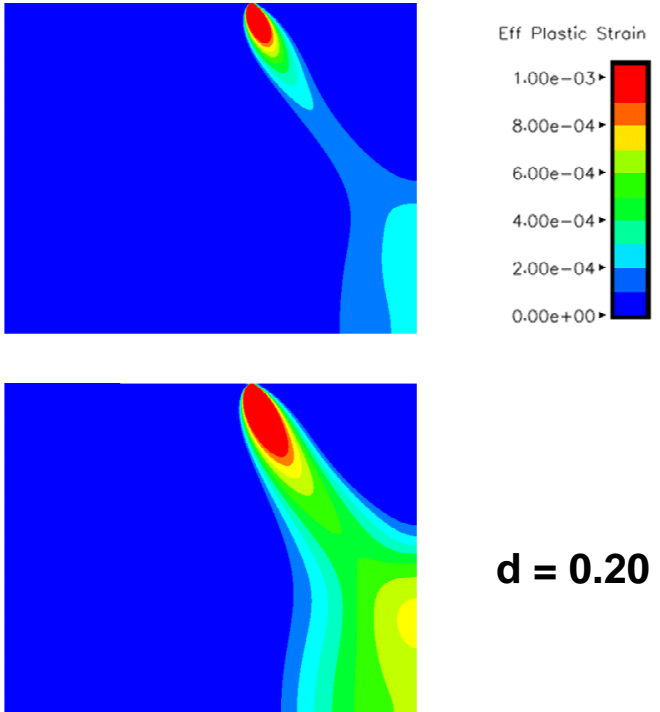

$d=0.20$
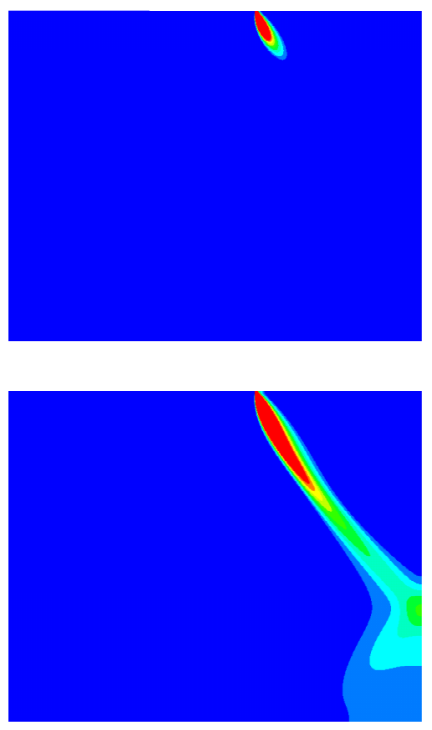

$d=0.24$

NL5B
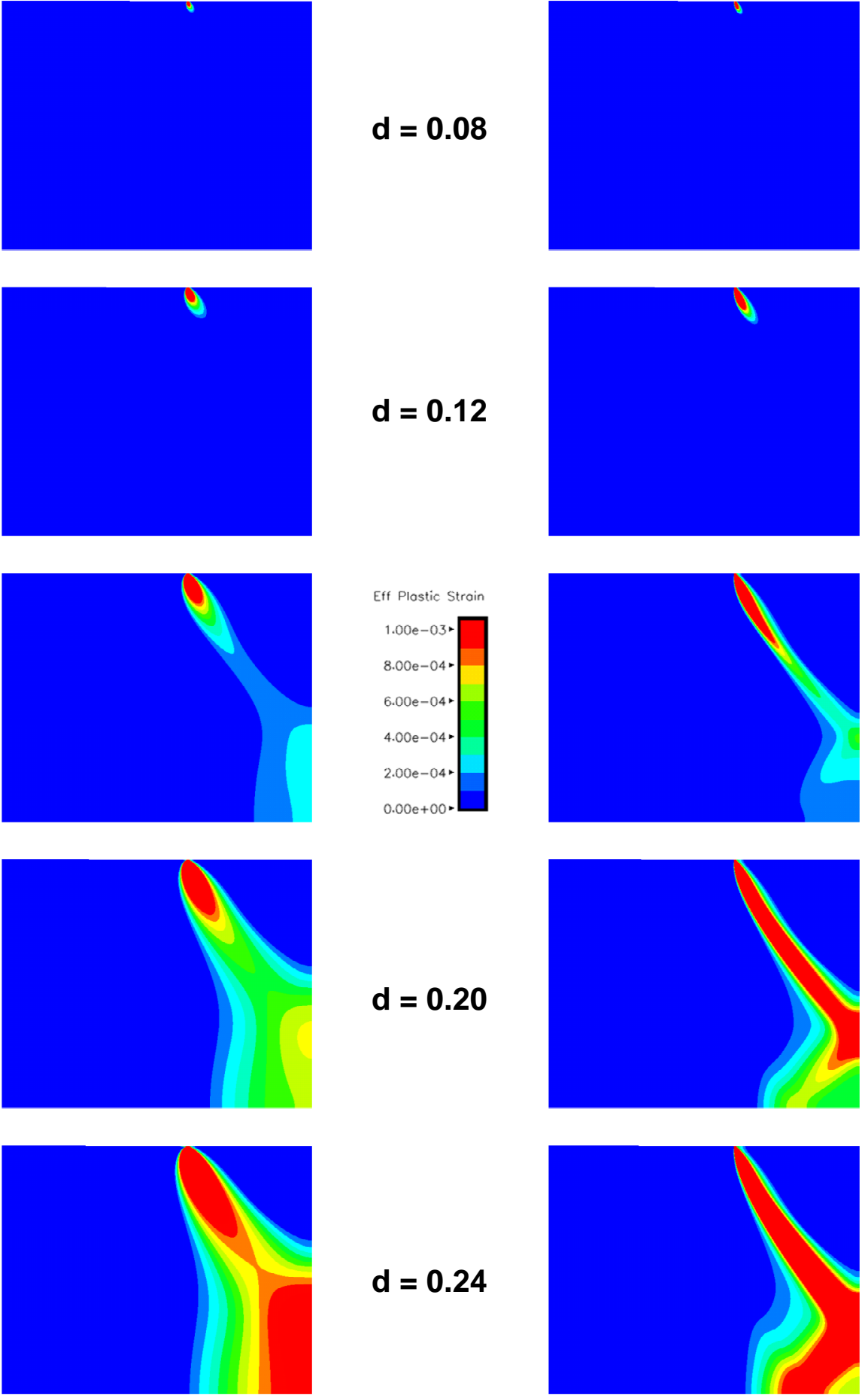

Figure 9 - Contours of effective plastic strain for NL5A and NL5B for mesh density $n=6$ at punch displacements of $0.08,0.12,0.16,0.20$ and 0.24 units, respectively. 


\section{Conclusions/Issue}

Given the NAFEMS reference solutions are numerical solution with quadratic elements, a direct "apples-to-apples" comparison for NIKE3D is not possible at this time. MDG codes have historically relied upon low-order elements due to their robustness in the presence of large deformations and especially contact. This will likely change in the future, but for now, relevant comparisons have been made between the existing capability and the benchmarks.

For NL5A with strain hardening plasticity, the $\mathrm{n}=4$ mesh provides the closest RMS match to the NAFEMS reference solution. Again, this corresponds to using an $8 \times 8$ patch of linear elements in place of a single quadratic element, showing the representational power of the higher-order element. However, even the $n=3$ results are within credible engineering agreement with the benchmark and represents less uncertainty in the numerical method than probably exists in typical mechanical properties of materials. The results for $\mathrm{n}=5$ and 6 are computational overkill for practical purposes, but they confirm the convergence behavior of the numerical discretization and NIKE3D's implementation.

Comparing the reference solution for benchmark NL5B with perfect plasticity to the NIKE3D solutions, very large discrepancies appear even as the NIKE3D mesh is refined. We have documented the convergence of the NIKE3D solution and believe it to be a more realistic representation of the actual response. NAFEMS benchmark NL5B was understandably defined to use the same mesh as NL5A, however it appears to be inadequate to resolve the narrow flow bands arising from the perfect plasticity idealization. We should note that this does not invalidate benchmark NL5B as a verification problem if one has identical quadratic element technology, but it does make it more ambiguous when comparing differing technologies.

\section{References}

D. Linkens, "Selected Benchmarks for Material Non-Linearity," NAFEMS Ref. R0026

Rev. 1, January 1993. 


\section{NAFEMS definition for Benchmark NL5A}

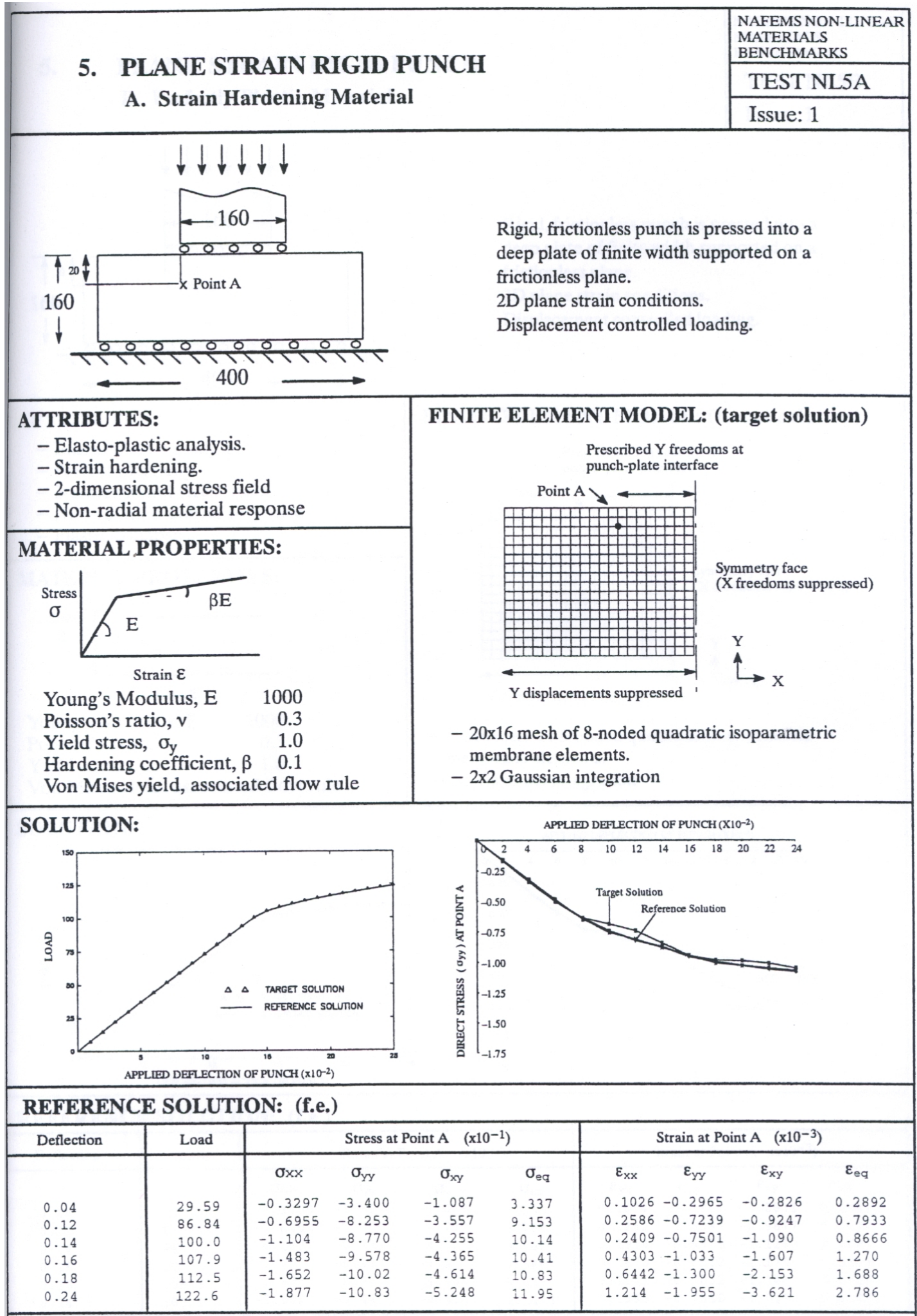

Note: Stresses and strains are extrapolated to Point A using gauss point values from element at its upper left 


\section{NAFEMS definition for Benchmark NL5B}

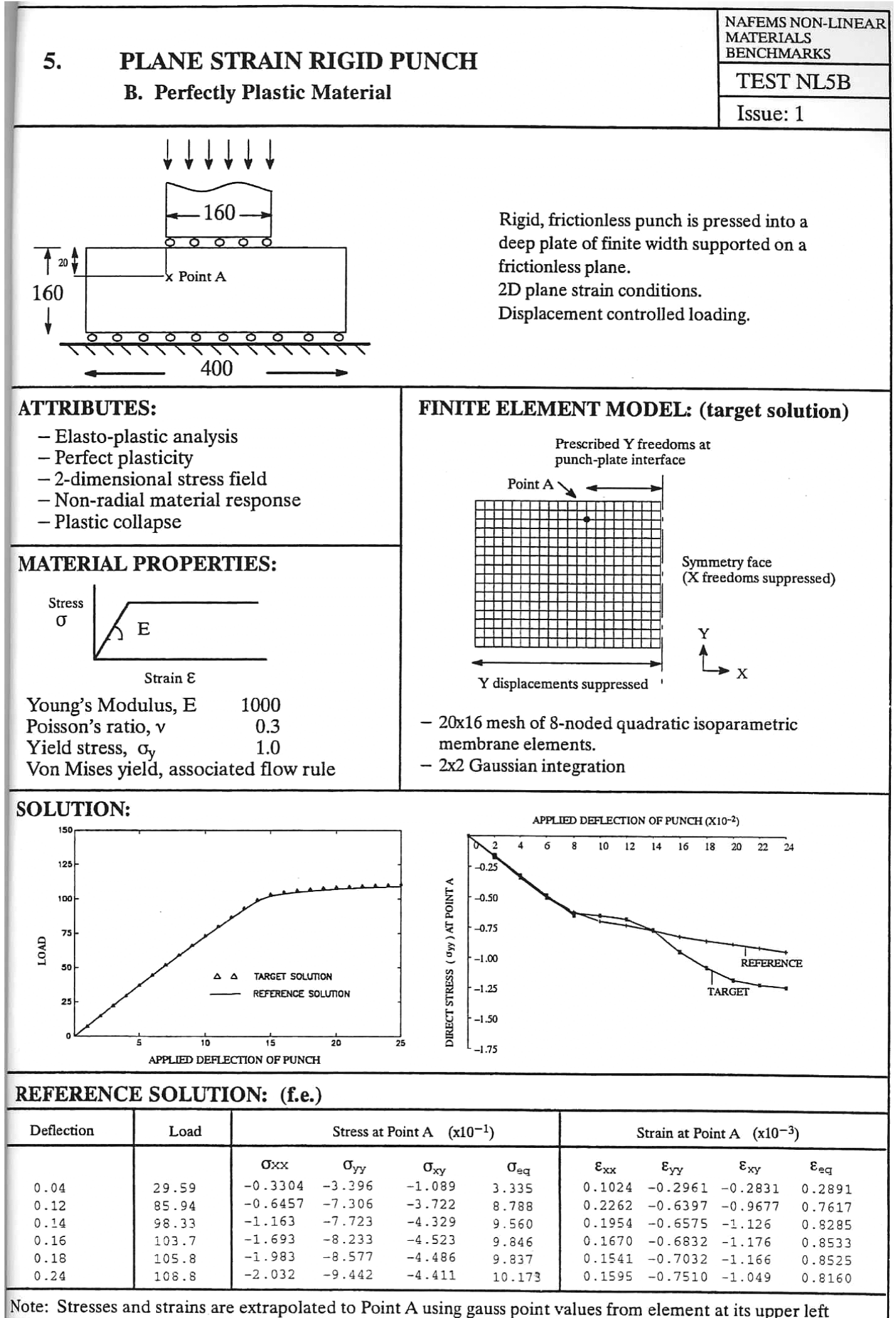

Note: Stresses and strains are extrapolated to Point A using gauss point values from element at its upper left 


\section{Appendix A}

Detailed stress data for problem NL5A.

\begin{tabular}{|c|c|c|c|c|}
\hline & \multicolumn{4}{|c|}{ Normal Stress } \\
\hline Displacement & Reference & NIKE3D & difference & $\%$ difference \\
\hline 0.04 & -0.3400 & -0.3392 & 0.0008 & 0.23 \\
\hline 0.12 & -0.8253 & -0.9386 & -0.1133 & -13.73 \\
\hline 0.14 & -0.8770 & -1.0345 & -0.1575 & -17.96 \\
\hline 0.16 & -0.9578 & -1.1040 & -0.1462 & -15.26 \\
\hline 0.18 & -1.0020 & -1.1462 & -0.1442 & -14.39 \\
\hline 0.24 & -1.0830 & -1.2195 & -0.1365 & -12.60 \\
\hline \multicolumn{4}{|c|}{ RMS Average \% difference } & 13.60 \\
\hline
\end{tabular}

Table A1 - Normal stress $\sigma_{\mathrm{yy}}$ at Point A for mesh density $\mathrm{n}=1$.

\begin{tabular}{|c|c|c|c|c|}
\cline { 2 - 5 } \multicolumn{1}{c|}{} & \multicolumn{4}{c|}{ Normal Stress } \\
\hline Displacement & Reference & NIKE3D & difference & $\%$ difference \\
\hline 0.04 & -0.3400 & -0.3434 & -0.0034 & -1.01 \\
\hline 0.12 & -0.8253 & -0.8791 & -0.0538 & -6.52 \\
\hline 0.14 & -0.8770 & -0.9615 & -0.0845 & -9.63 \\
\hline 0.16 & -0.9578 & -1.0284 & -0.0706 & -7.38 \\
\hline 0.18 & -1.0020 & -1.0628 & -0.0608 & -6.07 \\
\hline 0.24 & -1.0830 & -1.1438 & -0.0608 & -5.61 \\
\hline \multicolumn{5}{|c|}{ RMS Average \% difference } \\
\hline
\end{tabular}

Table A 2 - Normal stress $\sigma_{\mathrm{yy}}$ at Point A for mesh density $\mathrm{n}=2$.

\begin{tabular}{|c|c|c|c|c|}
\hline & \multicolumn{4}{|c|}{ Normal Stress } \\
\hline Displacement & Reference & NIKE3D & difference & $\%$ difference \\
\hline 0.04 & -0.3400 & -0.3420 & -0.0020 & -0.58 \\
\hline 0.12 & -0.8253 & -0.8339 & -0.0086 & -1.05 \\
\hline 0.14 & -0.8770 & -0.9071 & -0.0301 & -3.43 \\
\hline 0.16 & -0.9578 & -0.9821 & -0.0243 & -2.54 \\
\hline 0.18 & -1.0020 & -1.0253 & -0.0233 & -2.33 \\
\hline 0.24 & -1.0830 & -1.1059 & -0.0229 & -2.11 \\
\hline \multicolumn{4}{|c|}{ RMS Average \% difference } & 2.23 \\
\hline
\end{tabular}

Table A3 - Normal stress $\sigma_{\mathrm{yy}}$ at Point A for mesh density $\mathrm{n}=3$. 


\begin{tabular}{|c|c|c|c|c|}
\cline { 2 - 5 } \multicolumn{1}{c|}{} & \multicolumn{4}{c|}{ Normal Stress } \\
\hline Displacement & Reference & NIKE3D & difference & $\%$ difference \\
\hline 0.04 & -0.3400 & -0.3388 & 0.0012 & 0.35 \\
\hline 0.12 & -0.8253 & -0.8184 & 0.0069 & 0.84 \\
\hline 0.14 & -0.8770 & -0.8811 & -0.0041 & -0.47 \\
\hline 0.16 & -0.9578 & -0.9602 & -0.0024 & -0.25 \\
\hline 0.18 & -1.0020 & -1.0068 & -0.0048 & -0.48 \\
\hline 0.24 & -1.0830 & -1.0864 & -0.0034 & -0.31 \\
\hline \multicolumn{4}{|c|}{ RMS Average \% difference } & $\mathbf{0 . 4 9}$ \\
\hline
\end{tabular}

Figure A4 - Normal stress $\sigma_{y y}$ at Point A for mesh density $n=4$.

\begin{tabular}{|c|c|c|c|c|}
\cline { 2 - 5 } \multicolumn{1}{c|}{} & \multicolumn{4}{c|}{ Normal Stress } \\
\hline Displacement & Reference & NIKE3D & difference & \% difference \\
\hline 0.04 & -0.3400 & -0.3368 & 0.0032 & 0.95 \\
\hline 0.12 & -0.8253 & -0.8135 & 0.0118 & 1.42 \\
\hline 0.14 & -0.8770 & -0.8709 & 0.0061 & 0.69 \\
\hline 0.16 & -0.9578 & -0.9542 & 0.0036 & 0.38 \\
\hline 0.18 & -1.0020 & -1.0010 & 0.0010 & 0.10 \\
\hline 0.24 & -1.0830 & -1.0814 & 0.0016 & 0.15 \\
\hline \multicolumn{4}{|c|}{ RMS Average \% difference } & $\mathbf{0 . 7 7}$ \\
\hline
\end{tabular}

Figure A5 - Normal stress $\sigma_{y y}$ at Point A for mesh density $n=5$.

\begin{tabular}{|c|c|c|c|c|}
\cline { 2 - 5 } \multicolumn{1}{c|}{} & \multicolumn{4}{c|}{ Normal Stress } \\
\hline Displacement & Reference & NIKE3D & difference & $\%$ difference \\
\hline 0.04 & -0.3400 & -0.3357 & 0.0043 & 1.27 \\
\hline 0.12 & -0.8253 & -0.8115 & 0.0138 & 1.67 \\
\hline 0.14 & -0.8770 & -0.8662 & 0.0108 & 1.24 \\
\hline 0.16 & -0.9578 & -0.9513 & 0.0065 & 0.68 \\
\hline 0.18 & -1.0020 & -0.9982 & 0.0038 & 0.38 \\
\hline 0.24 & -1.0830 & -1.0778 & 0.0052 & 0.48 \\
\hline \multicolumn{4}{|c|}{ RMS Average \% difference } & $\mathbf{1 . 0 6}$ \\
\hline
\end{tabular}

Table A6 - Normal stress $\sigma_{\mathrm{yy}}$ at Point A for mesh density $\mathrm{n}=6$. 


\begin{tabular}{|c|c|c|c|c|}
\cline { 2 - 5 } \multicolumn{1}{c|}{} & \multicolumn{4}{c|}{ Normal Stress } \\
\hline Displacement & Reference & NIKE3D & difference & $\%$ difference \\
\hline 0.04 & -0.3400 & -0.3389 & 0.0011 & 0.33 \\
\hline 0.12 & -0.8253 & -0.8191 & 0.0062 & 0.74 \\
\hline 0.14 & -0.8770 & -0.8819 & -0.0049 & -0.56 \\
\hline 0.16 & -0.9578 & -0.9613 & -0.0035 & -0.36 \\
\hline 0.18 & -1.0020 & -1.0083 & -0.0063 & -0.63 \\
\hline 0.24 & -1.0830 & -1.0891 & -0.0061 & -0.56 \\
\hline \multicolumn{4}{|c|}{ RMS Average \% difference } & $\mathbf{0 . 5 5}$ \\
\hline
\end{tabular}

Figure A7 - Normal stress $\sigma_{\mathrm{yy}}$ at Point A for mesh density $\mathrm{n}=4$ using NIKE3D's small deformation, linear kinematics option (cf. Table A4). 


\section{Appendix B}

Detailed stress data for problem NL5B.

\begin{tabular}{|c|c|c|c|c|}
\hline & \multicolumn{4}{|c|}{ Normal Stress } \\
\hline Displacement & Reference & NIKE3D & difference & $\%$ difference \\
\hline 0.04 & -0.3396 & -0.3392 & 0.0004 & 0.12 \\
\hline 0.12 & -0.7306 & -0.9234 & -0.1928 & -26.39 \\
\hline 0.14 & -0.7723 & -1.0005 & -0.2282 & -29.55 \\
\hline 0.16 & -0.8233 & -1.0459 & -0.2226 & -27.04 \\
\hline 0.18 & -0.8577 & -1.0609 & -0.2032 & -23.69 \\
\hline 0.24 & -0.9442 & -1.0435 & -0.0993 & -10.52 \\
\hline \multicolumn{4}{|c|}{ RMS Average \% difference } & 22.26 \\
\hline
\end{tabular}

Table B1 - Normal stress $\sigma_{\mathrm{yy}}$ at Point A for mesh density $\mathrm{n}=1$.

\begin{tabular}{|c|c|c|c|c|}
\cline { 2 - 5 } \multicolumn{1}{c|}{} & \multicolumn{4}{c|}{ Normal Stress } \\
\hline Displacement & Reference & NIKE3D & difference & \% difference \\
\hline 0.04 & -0.3396 & -0.3434 & -0.0038 & -1.12 \\
\hline 0.12 & -0.7306 & -0.8383 & -0.1077 & -14.74 \\
\hline 0.14 & -0.7723 & -0.8937 & -0.1214 & -15.72 \\
\hline 0.16 & -0.8233 & -0.9401 & -0.1168 & -14.19 \\
\hline 0.18 & -0.8577 & -0.9590 & -0.1013 & -11.81 \\
\hline 0.24 & -0.9442 & -0.9443 & -0.0001 & -0.01 \\
\hline \multicolumn{4}{|c|}{ RMS Average \% difference } & 11.59 \\
\hline
\end{tabular}

Table B2 - Normal stress $\sigma_{\mathrm{yy}}$ at Point A for mesh density $\mathrm{n}=2$.

\begin{tabular}{|c|c|c|c|c|}
\cline { 2 - 5 } \multicolumn{1}{c|}{} & \multicolumn{4}{c|}{ Normal Stress } \\
\hline Displacement & Reference & NIKE3D & difference & \% difference \\
\hline 0.04 & -0.3396 & -0.3419 & -0.0023 & -0.68 \\
\hline 0.12 & -0.7306 & -0.7656 & -0.0350 & -4.79 \\
\hline 0.14 & -0.7723 & -0.7910 & -0.0187 & -2.42 \\
\hline 0.16 & -0.8233 & -0.8313 & -0.0080 & -0.97 \\
\hline 0.18 & -0.8577 & -0.8640 & -0.0063 & -0.73 \\
\hline 0.24 & -0.9442 & -0.8833 & 0.0609 & 6.45 \\
\hline \multicolumn{4}{|c|}{ RMS Average \% difference } & 3.47 \\
\hline
\end{tabular}

Table B3 - Normal stress $\sigma_{\mathrm{yy}}$ at Point A for mesh density $\mathrm{n}=3$. 


\begin{tabular}{|c|c|c|c|c|}
\cline { 2 - 5 } \multicolumn{1}{c|}{} & \multicolumn{4}{c|}{ Normal Stress } \\
\hline Displacement & Reference & NIKE3D & difference & \% difference \\
\hline 0.04 & -0.3396 & -0.3385 & 0.0011 & 0.32 \\
\hline 0.12 & -0.7306 & -0.7348 & -0.0042 & -0.57 \\
\hline 0.14 & -0.7723 & -0.7476 & 0.0247 & 3.20 \\
\hline 0.16 & -0.8233 & -0.7663 & 0.0570 & 6.92 \\
\hline 0.18 & -0.8577 & -0.7905 & 0.0672 & 7.83 \\
\hline 0.24 & -0.9442 & -0.8380 & 0.1062 & 11.25 \\
\hline \multicolumn{5}{|c|}{ RMS Average \% difference } \\
\hline
\end{tabular}

Table B4 - Normal stress $\sigma_{\mathrm{yy}}$ at Point A for mesh density $\mathrm{n}=4$.

\begin{tabular}{|c|c|c|c|c|}
\cline { 2 - 5 } \multicolumn{1}{c|}{} & \multicolumn{4}{c|}{ Normal Stress } \\
\hline Displacement & Reference & NIKE3D & difference & \% difference \\
\hline 0.04 & -0.3396 & -0.3360 & 0.0036 & 1.07 \\
\hline 0.12 & -0.7306 & -0.7233 & 0.0073 & 1.00 \\
\hline 0.14 & -0.7723 & -0.7397 & 0.0326 & 4.22 \\
\hline 0.16 & -0.8233 & -0.7578 & 0.0655 & 7.96 \\
\hline 0.18 & -0.8577 & -0.7759 & 0.0818 & 9.54 \\
\hline 0.24 & -0.9442 & -0.8184 & 0.1258 & 13.33 \\
\hline \multicolumn{4}{c|}{ RMS Average \% difference } & 7.66 \\
\hline
\end{tabular}

Table B5 - Normal stress $\sigma_{\mathrm{yy}}$ at Point A for mesh density $\mathrm{n}=5$.

\begin{tabular}{|c|c|c|c|c|}
\cline { 2 - 5 } \multicolumn{1}{c|}{} & \multicolumn{4}{c|}{ Normal Stress } \\
\hline Displacement & Reference & NIKE3D & difference & \% difference \\
\hline 0.04 & -0.3396 & -0.3342 & 0.0054 & 1.59 \\
\hline 0.12 & -0.7306 & -0.7177 & 0.0129 & 1.76 \\
\hline 0.14 & -0.7723 & -0.7354 & 0.0369 & 4.77 \\
\hline 0.16 & -0.8233 & -0.7541 & 0.0692 & 8.40 \\
\hline 0.18 & -0.8577 & -0.7717 & 0.0860 & 10.03 \\
\hline 0.24 & -0.9442 & -0.8103 & 0.1339 & 14.18 \\
\hline \multicolumn{4}{|c|}{ RMS Average \% difference } & 8.17 \\
\hline
\end{tabular}

Table B6 - Normal stress $\sigma_{\mathrm{yy}}$ at Point A for mesh density $\mathrm{n}=6$. 


\title{
Cyclic Thermal Loading of Two-Bar Assembly
}

\author{
NAFEMS Benchmarks NL3 and NL2A \\ Ryan Greer and Robert Ferencz \\ July and November 2003
}

\section{Introduction}

A simple two bar assembly is loaded axially bringing the material to 75 percent of its yield stress. Subsequently one bar is subjected to a cyclic temperature history to generate ratcheting and alternating plasticity in the bars. Note this is ratcheting in a macroscopic sense due to the interaction of the two bars and is not an intrinsic part of the local material model. The (homogeneous) mechanical strain and axial force in each bar are analyzed. NIKE3D solutions are compared to NAFEMS benchmark NL3 and NL2A, shown on pages 11 and 12, respectively. Geometrically identical, the first benchmark exercises perfect plasticity, while the second exercises strain hardening.

\section{Definition and Approach}

The problem consists of two bars ten units long, a unit square cross-section, and separated by one unit. The two bars are fixed at one end and constrained to move all nodes together in the $x$ direction at the other end. The $y$ displacement is suppressed on the bottom face of each bar and the $z$ displacement is suppressed on one transverse face of each bar. These $y$ and $z$ boundary conditions prevent any rigid body displacements but allow stress-free lateral expansion and contraction. The material properties described in the NAFEMS documentation were used. Both bars were modeled with NIKE3D's thermal-elastic-plastic Model 4. It should be noted that this model only supports isotropic hardening, whereas benchmark NL2A documents results with kinematic hardening. The lower bar was defined to have a CTE of zero, thus as desired by the benchmarks its behavior corresponds to remaining at a constant temperature of zero.

The mesh used consisted of ten elements in each bar. Only one mesh was created since the homogeneous, 1D solution was not dependent on mesh size. The elements are 8-node linear bricks: one unit long, one unit high, and one unit wide. The simulations used the linear kinematics (small deformation) option, as we were convinced this was how the benchmark analytic answer was derived. All simulations were run with NIKE3D's default convergence tolerances. Final executions were made with version 3.4.0 dated September 26, 2003.

The top bar, following the NAFEMS documentation, will be labeled as Bar 1 and the bottom bar will be labeled as Bar 2. The two bars are first subjected to an axial load. Bar 1 is then subjected to an alternating temperature change following the time history in the NAFEMS summary. For clarification of some subsequent details the actual applied temperature load curve used with NIKE3D is shown on the following page in Figure 1. 


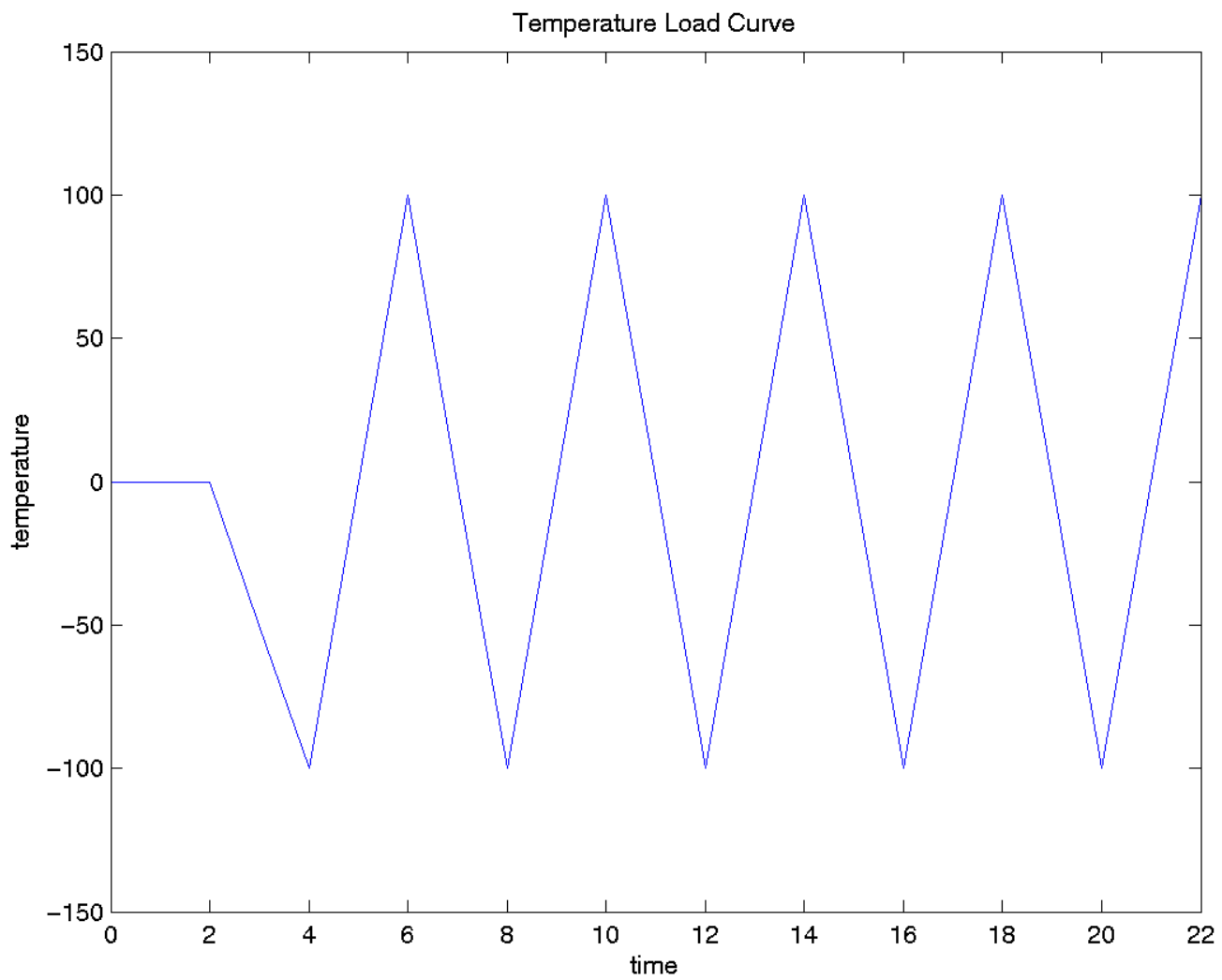

Figure 1 - Temperature load curve used for both benchmarks

The temperature load curve is zero for the first two time units because the mechanical load is applied linearly from zero up to the desired magnitude over that interval. The external mechanical load is then kept constant for all time thereafter. It should also be noted that the NAFEMS documentation refers to the temperature load curve in terms of half-cycles, or in other words the ordinal number of each peak. In Figure 1 we instead show the NIKE3D time values to clarify details of the load history.

For each benchmark two different simulations were performed using different size time steps. The first solution is equivalent to the NAFEMS solution in that the time step is 2.0 units. Thus after the mechanical loading each solution state corresponds to a peak on the temperature load curve. This solution was found to leave out some important aspects of the problem, mainly the onset of yielding at a smaller temperature excursion. As a result the other simulation used a time step size of 0.2 units. As will be seen in the results, this solution gives greater insight into the problem. For ease, the solution equivalent to the NAFEMS solution is referred to as the "peak-to-peak" solution and the other is referred to as the "plateau" solution. 


\section{Results for Benchmark NL3}

The mechanical and thermal loading previously described is applied to the assembly while dictating perfectly plastic response of the material. The mechanical strain for the "peak-to-peak" case is shown in Figure 2 and the axial load in Figure 3. The mechanical strain was calculated by sampling the total strain using Griz, then subtracting the appropriate $\alpha \Delta T$ thermal strain. Tables A1-A4 in Appendix A compare the mechanical strain and the axial load to the analytical solution found in the NAFEMS documentation. To align with the NAFEMS documentation, the peak numbers are referred to as halfcycles where half-cycle 1 is the first peak at a temperature of -100 , half-cycle 2 is the second peak at a temperature of 100 , and so on. Half-cycle 0 refers to the second time unit and represents the point where the mechanical load ceases to change. Clearly the results are in excellent agreement. The mechanical strain error is less than $0.06 \%$ and the axial force error less than $0.08 \%$.

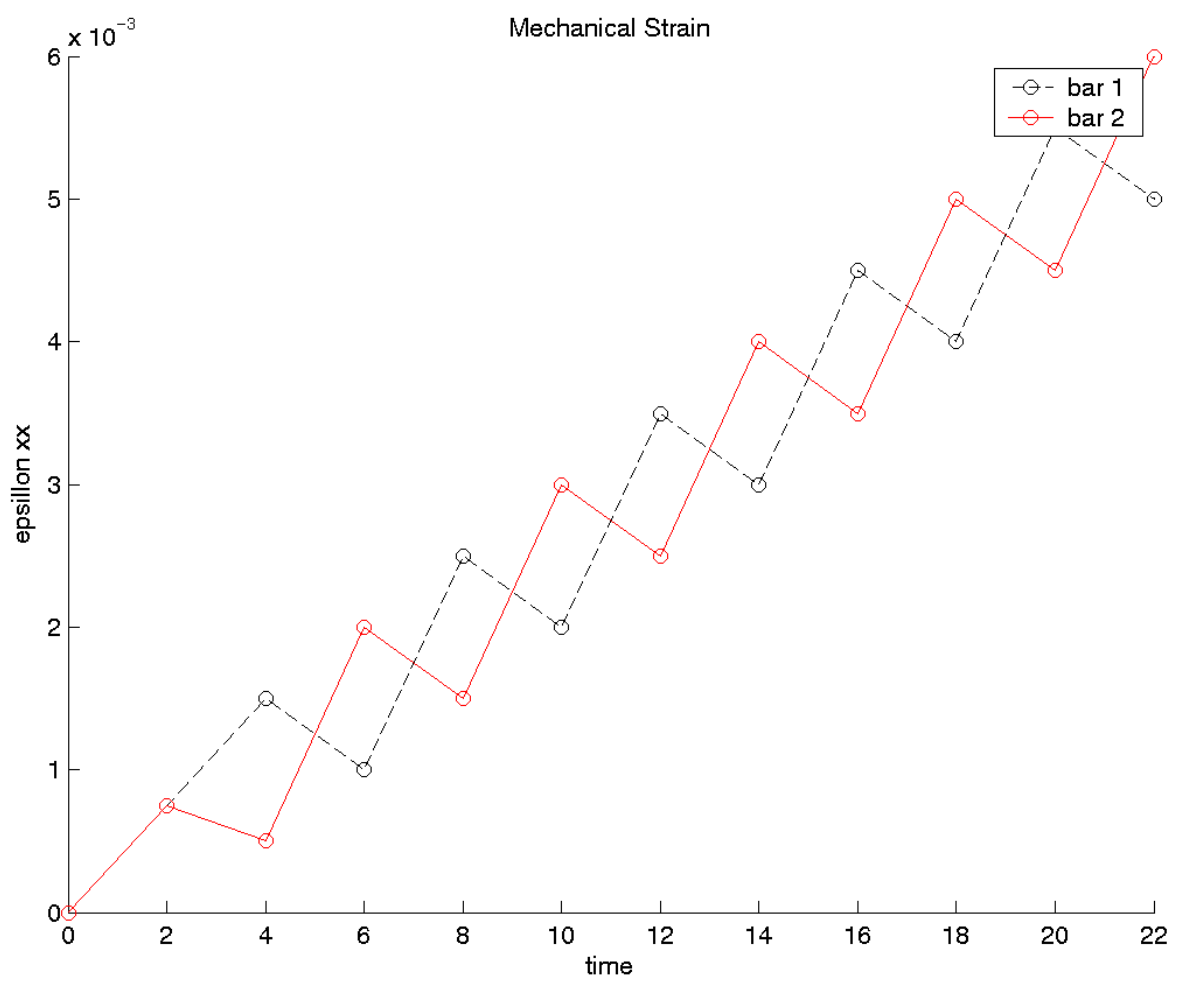

Figure 2 - Mechanical strains for problem NL3. 


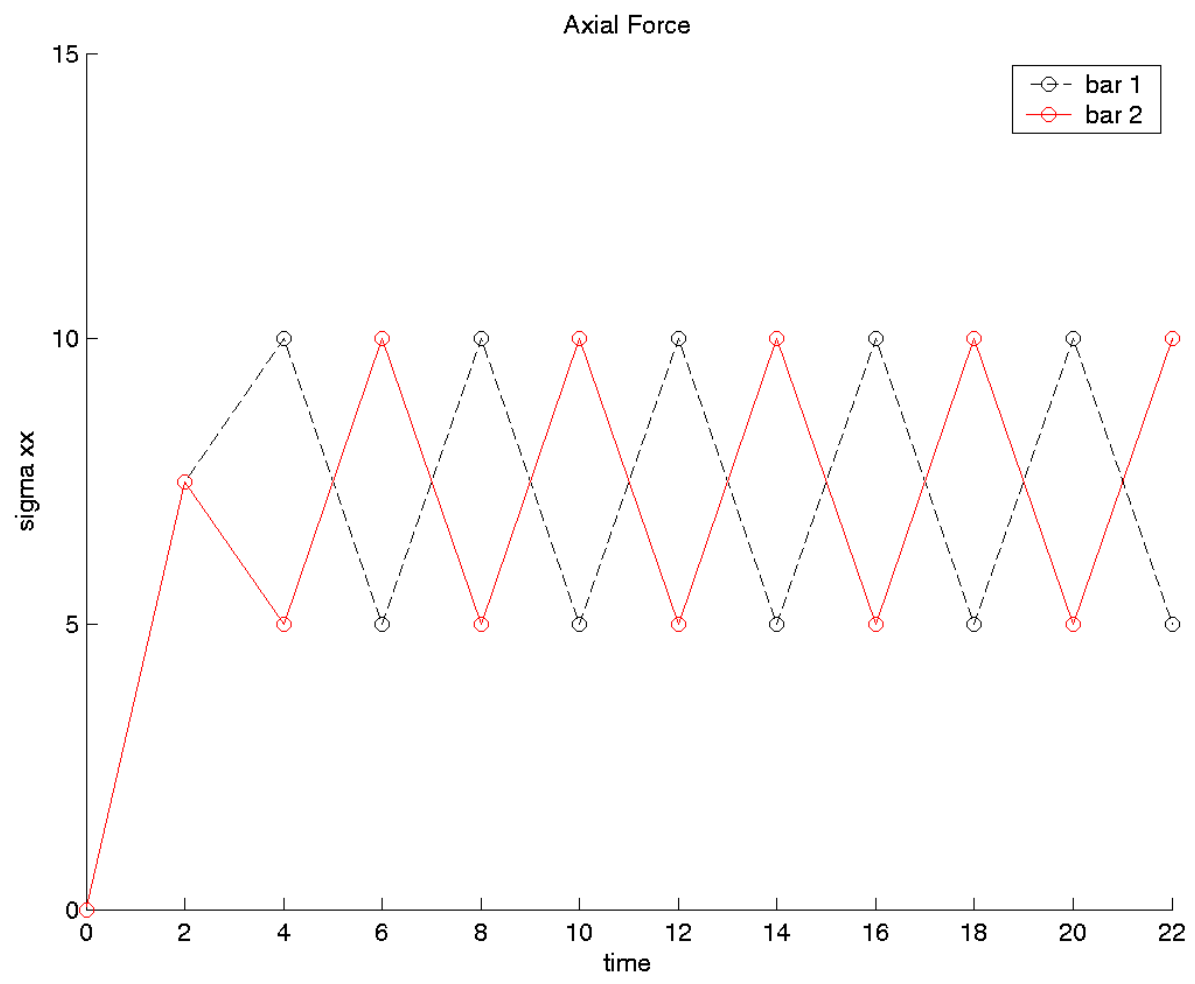

Figure 3 - Axial forces for problem NL3.

Figures 4 and 5 illustrate the "plateau" case. These demonstrate that the onset of yielding (or re-yielding) occurs prior to reaching the extreme temperature in any one half-cycle. These results are not meant to infer the published benchmark is invalid, rather to illustrate the richer behavior to be observed with greater temporal resolution. We also find it easier to visualize the interaction of the two bars. 


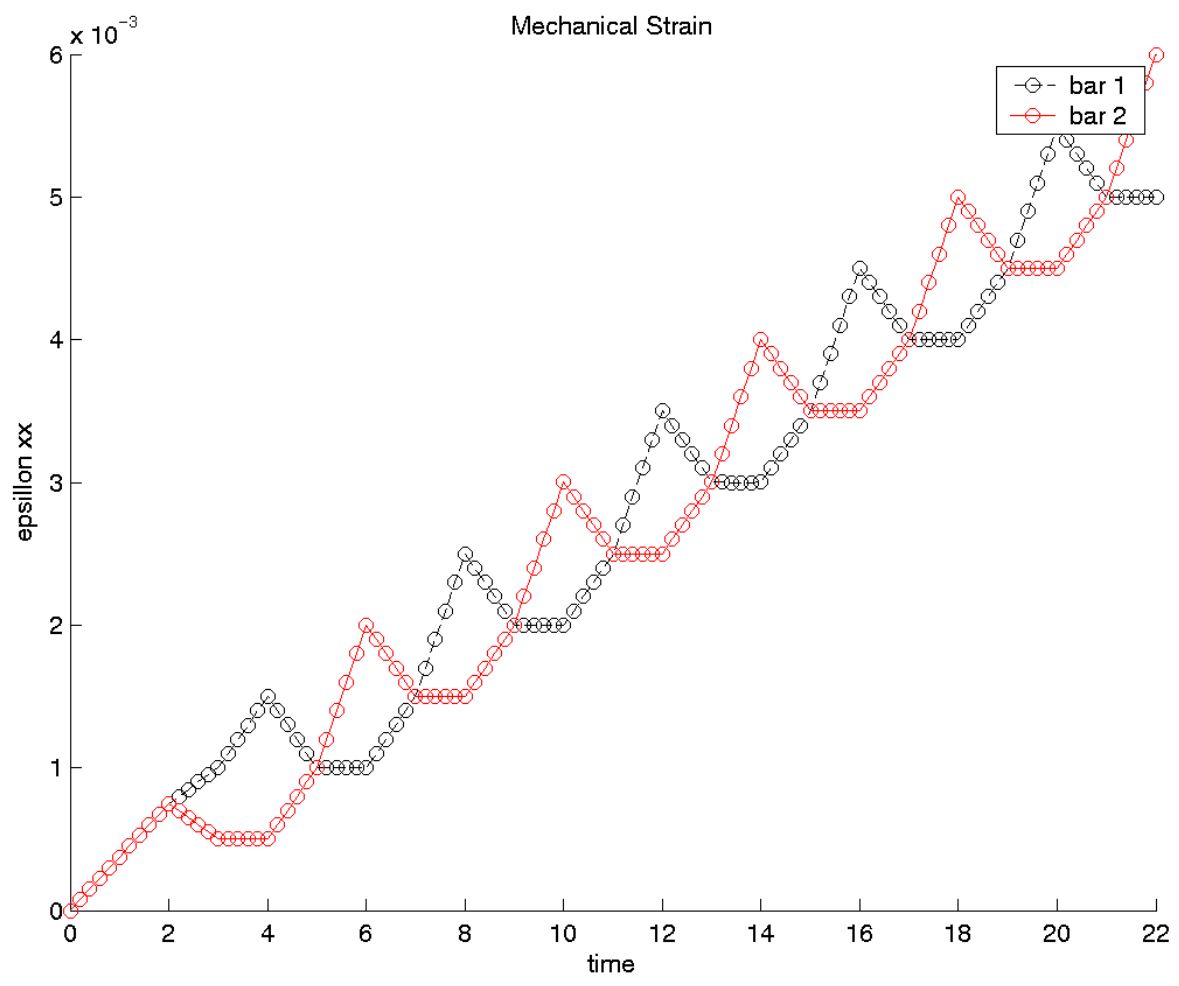

Figure 4 - Mechanical strain for problem NL3 with greater temporal resolution.

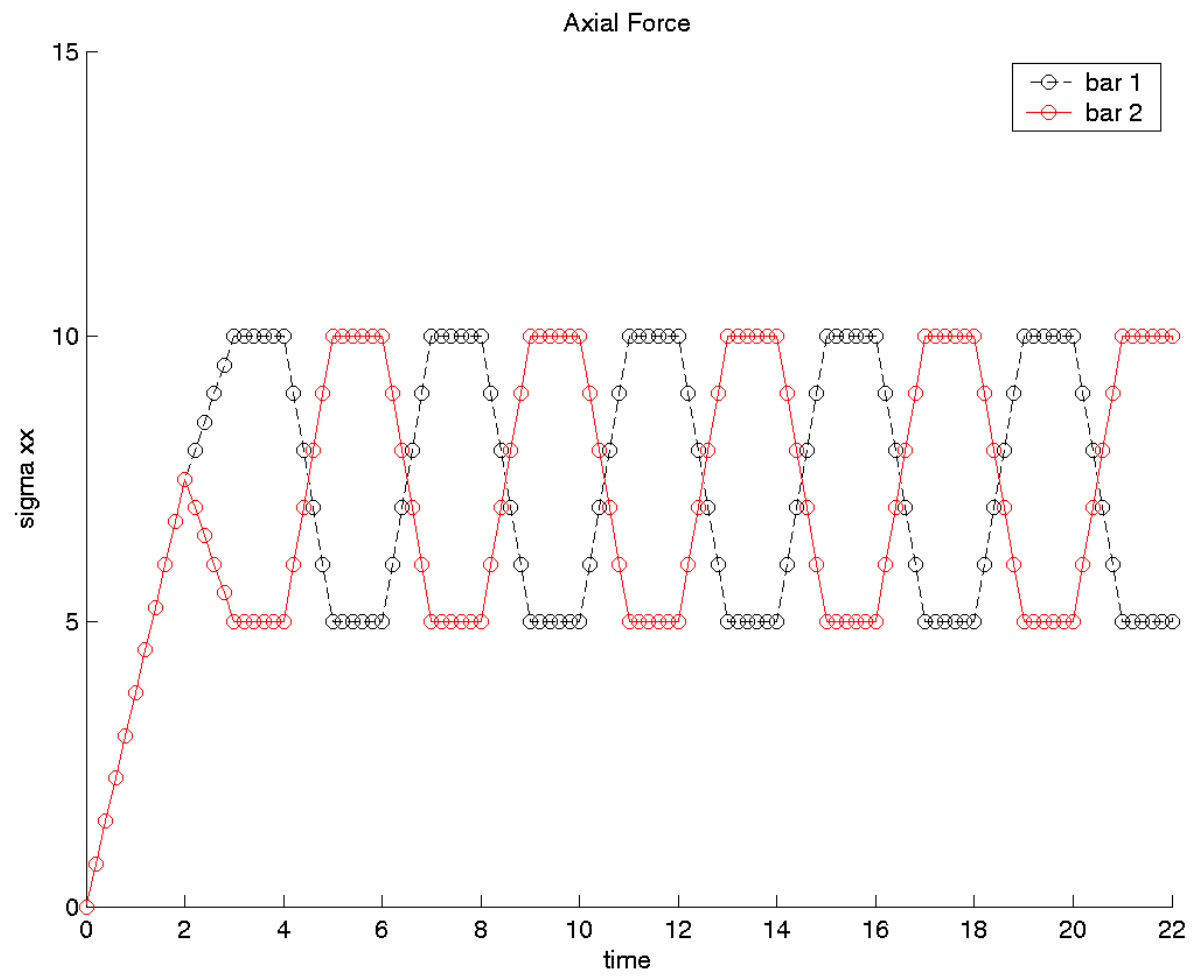

Figure 5 - Axial force for problem NL3 with greater temporal resolution. 


\section{Results for NL2A}

Benchmark NL2A utilizes the identical geometry and loading as NL3, but exercises strain hardening. As noted previously the NAFEMS benchmark used kinematic hardening, whereas with NIKE3D's material Model 4 only isotropic hardening can be specified. Indeed, for a general thermal-elastic-plastic model such as Model 4, it is not clear how the back stress associated with a kinematic hardening model should evolve with temperature.

The mechanical strain for the peak-to-peak case is shown in Figure 6 and the axial load is shown in Figure 7. Comparing Figures 3 and 7, the activation of hardening leads the extremes of the individual axial loads to progressively increase, though their total remains essentially constant at 15.0. Running the simulation for more cycles than dictated by the benchmark shows the response is essentially saturated after 30 half-cycles.

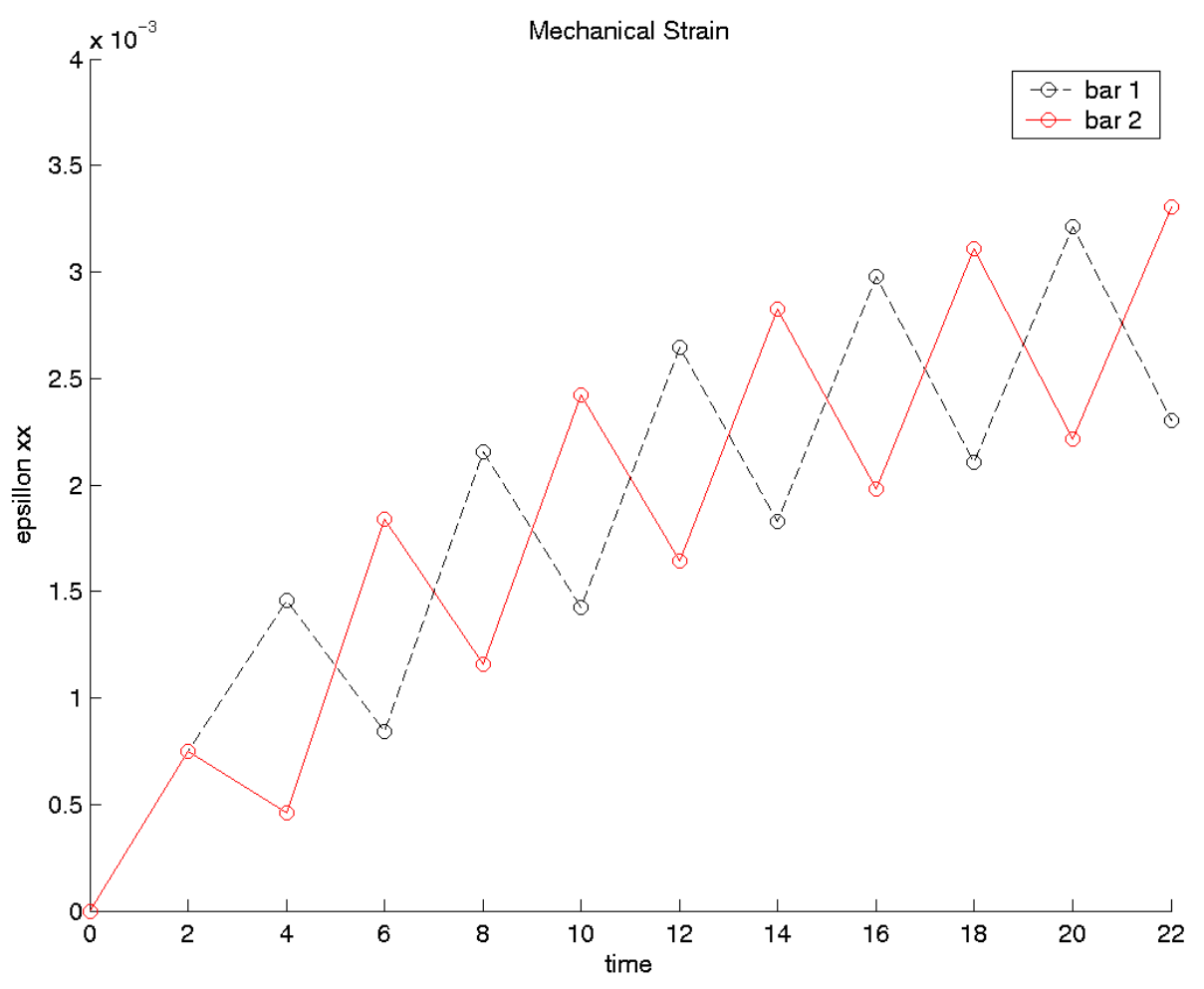

Figure 6 - Mechanical strain for case with hardening 


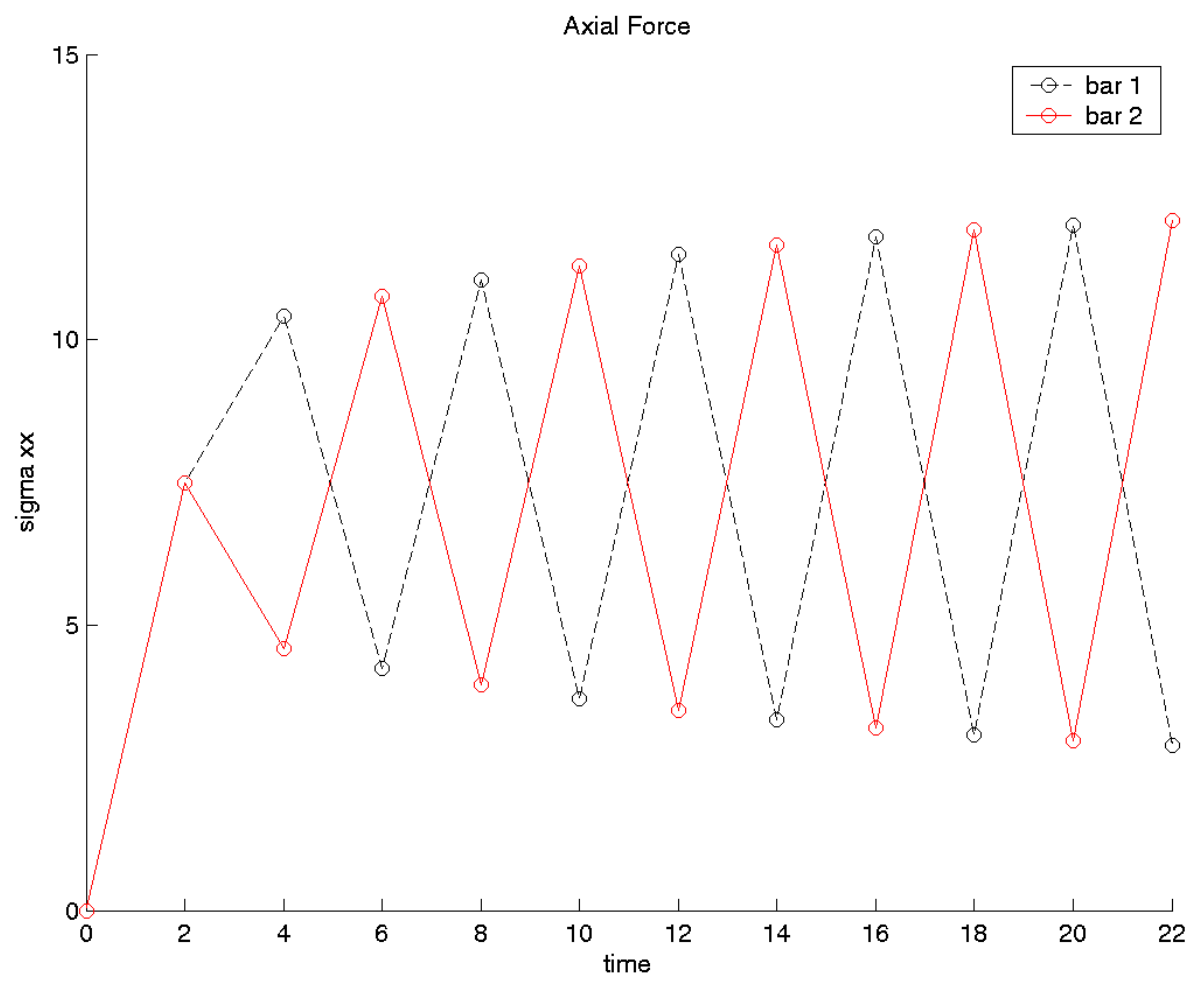

Figure 7 - Axial force for case with hardening

Tables B1-B4 in Appendix B provides direct comparisons of the mechanical strain and the axial load to the analytical solution found in the NAFEMS documentation. Figure 8 provides a visual summary, which shows the substantial differences between the NIKE3D run and the benchmark. The strain is different by more than six percent at the $10^{\text {th }}$ peak. This is not surprising given the difference in the hardening model, but it has proved unsatisfying to just leave the comparison at that, as other issues could be in play.

With some thought, it was recognized that the thermal response of the material is essentially used as just a loading mechanism, e.g., the properties are not temperature dependent. Therefore, a revised model was constructed that could largely use NIKE3D's material Model 3 with isothermal plasticity and kinematic hardening. In particular, the thermally-driven response of Bar 1 was isolated into a single element. It being one tenth the length of the overall bar, its CTE was increased 10X. This way the same total load could be induced in the bar for the same temperature excursion. To avoid inducing any non-axial stresses in Bar 1, this element was made nodally disjoint from the remaining bar, but rigid constraints defined for the $x$ displacements between the resulting two sets of four nodes. (Think of it as a perfectly rigid, frictionless contact surface between the two elements.) With this change the remaining elements in both Bar 1 and 2 could use Model 3 and exercise kinematic hardening. 


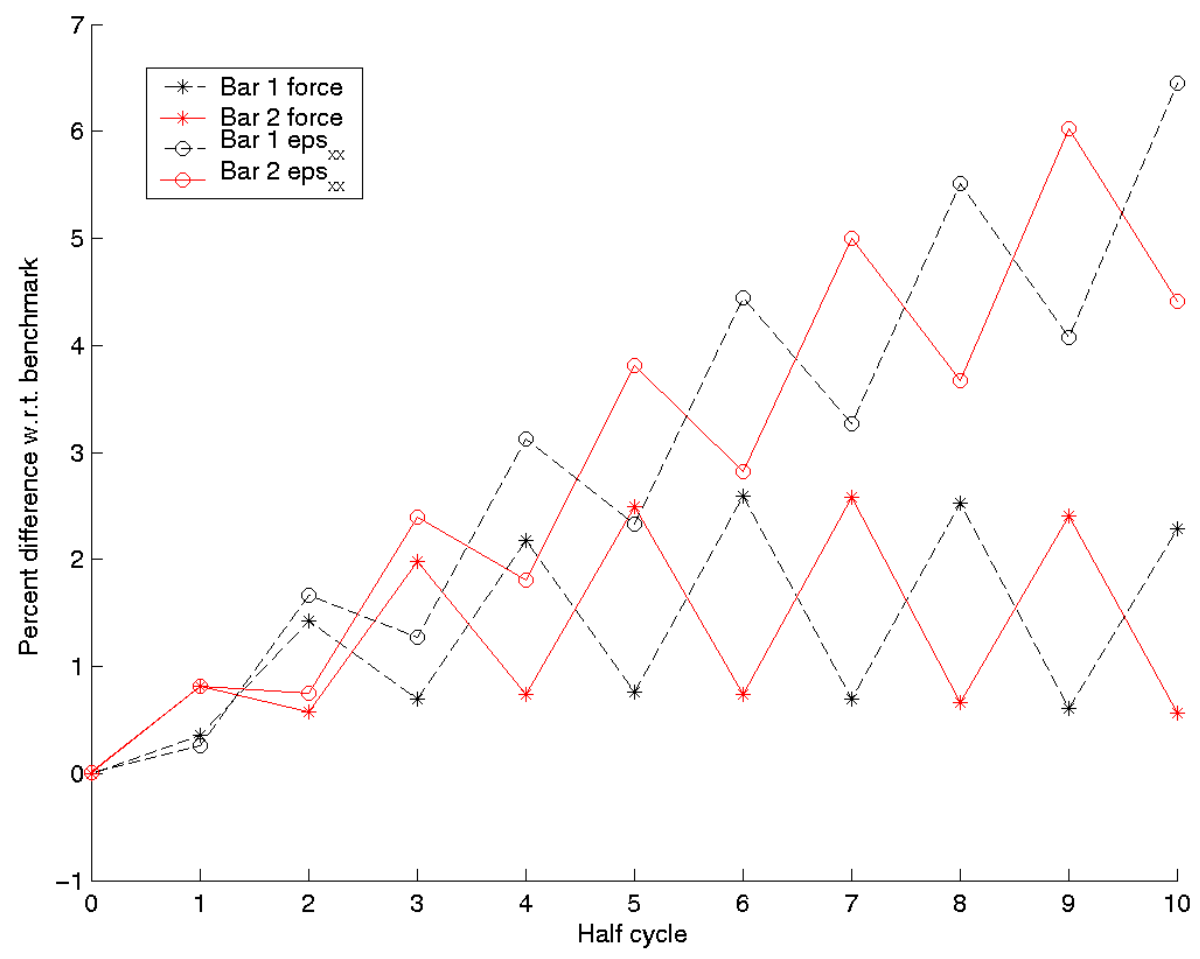

Figure 7 - Relative error in response for NL2A with original model.

The simulation was rerun using the revised FEA model just described. The detailed comparisons are listed in Tables $\mathrm{C} 1-\mathrm{C} 4$ of Appendix $\mathrm{C}$ and show excellent agreement with the benchmark. Both the mechanical strain and axial load agree within $0.1 \%$ relative error. Admittedly this revised model is imperfect, as the one element still utilizing isotropic hardening has a different axial strain. The higher strain there will cause a slight change elsewhere. To ensure that we had not simply "lucked out", we ran a second revised case where the isotropic hardening element was reduced to be only one-tenth its original length. To compensate its CTE was increased another 10X. This further localized the axial strain inhomogeneity. The response in the remaining elements of Bar 1 remained in close agreement with the benchmark result.

For completeness, the following two graphs are the data for the plateau case computed with the original model. With hardening active the plateaus are no longer perfectly flat. Furthermore, it is interesting to note that with hardening the plateaus become progressively "narrower" and it appears a form of "peak-to-peak" behavior is established near the end of the history. 


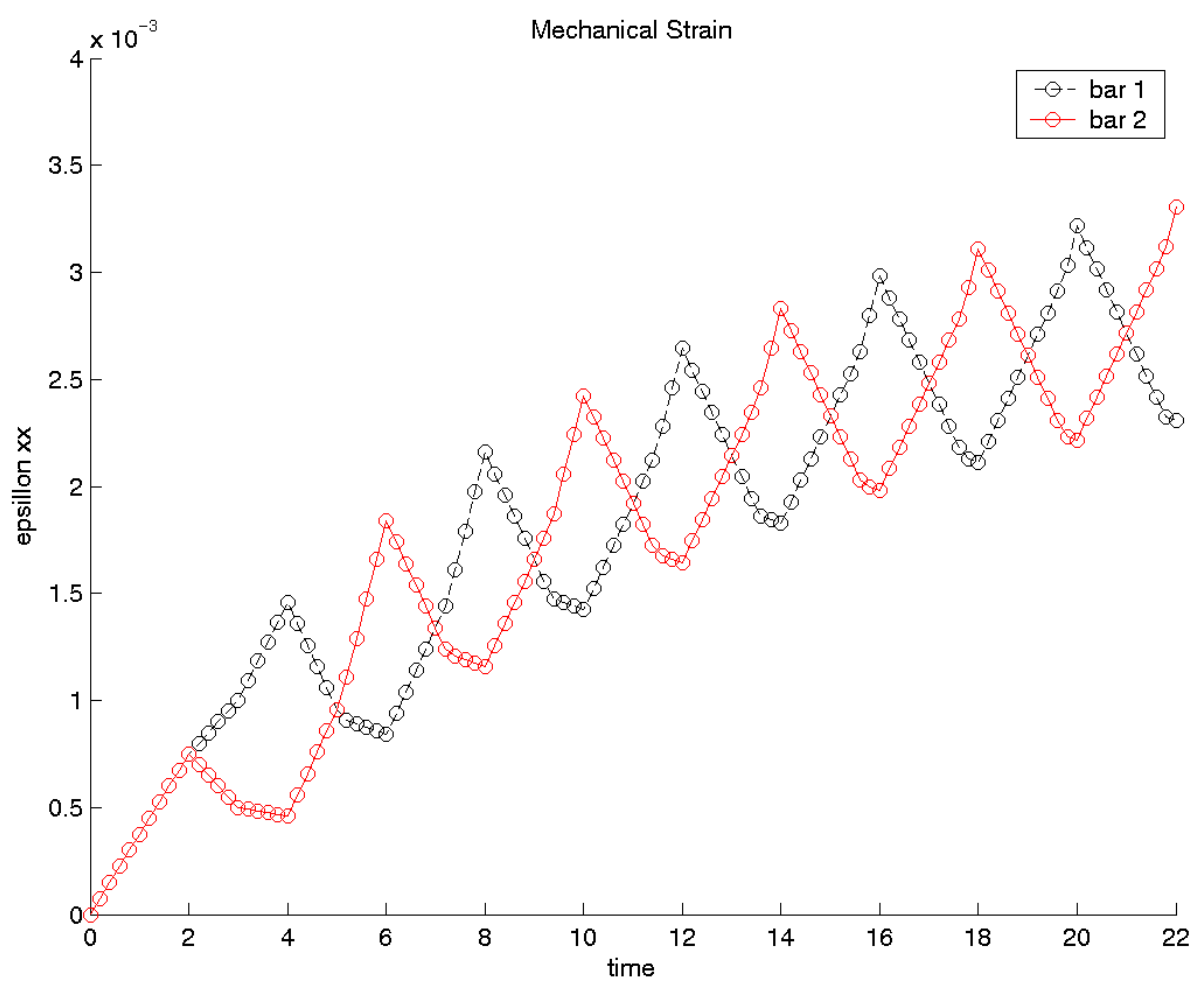

Figure 8 - Mechanical strain for problem NL2A with greater temporal resolution.

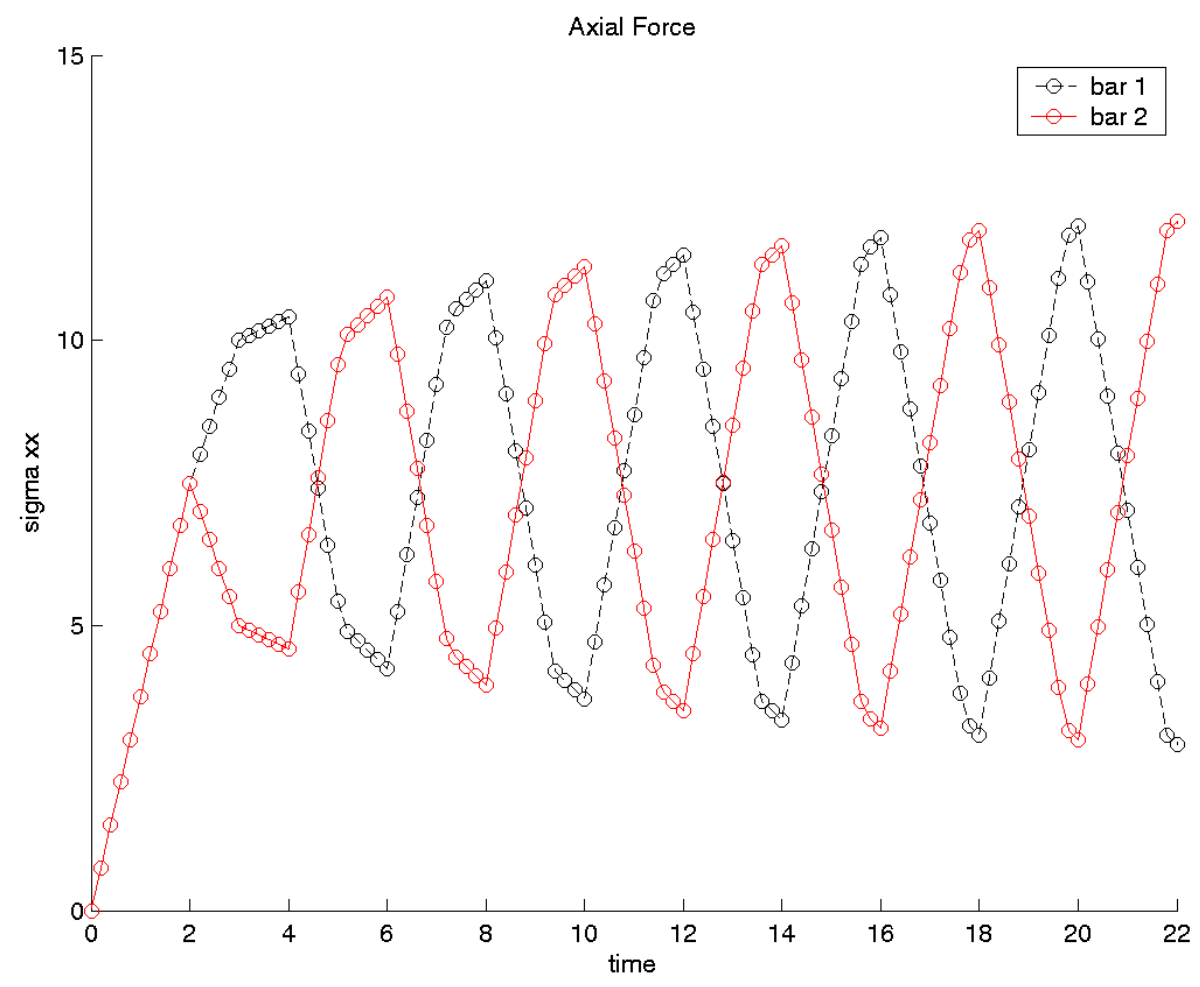

Figure 9 - Axial load for problem NL2A with greater temporal resolution. 


\section{Conclusions/Issues}

In comparison to the analytical solution shown in the NAFEMS documentation, the NIKE3D results for case NL3 (perfect plasticity) are excellent with all data points having less than $0.1 \%$ error. For case NL2A, uniformly using NIKE3D's material Model 4 with isotropic hardening leads to substantial differences from the published benchmark results. The mechanical strains differ by approximately $0.3 \%$ to $6.5 \%$; the axial loads differ by approximately $0.4 \%$ to $2.5 \%$. To ensure the only major difference was indeed the hardening law, a revised FEA model was created that permitted an isothermal, kinematic hardening model to be used for the majority of the material. This revised model shows excellent agreement with the benchmark, to within $0.1 \%$ relative error.

One small remaining open issue can be seen in Tables B1 and B3. The response at halfcycle one should entail a monotonic loading of Bar 1. In the absence of any unloading to that point, there should be no difference between an isotropic and kinematic hardening model for the plasticity. Thus we cannot explain the relative error of 0.26 and 0.36 percent in the mechanical strain and axial load, respectively. To be sure, these are not large differences, but they are about 10X larger than the results seen in Tables $\mathrm{C} 1$ and $\mathrm{C} 3$.

\section{References}

D. Linkens, "Selected Benchmarks for Material Non-Linearity," NAFEMS Ref. R0026 Rev. 1, January 1993. 
NAFEMS definition for Benchmark NL3

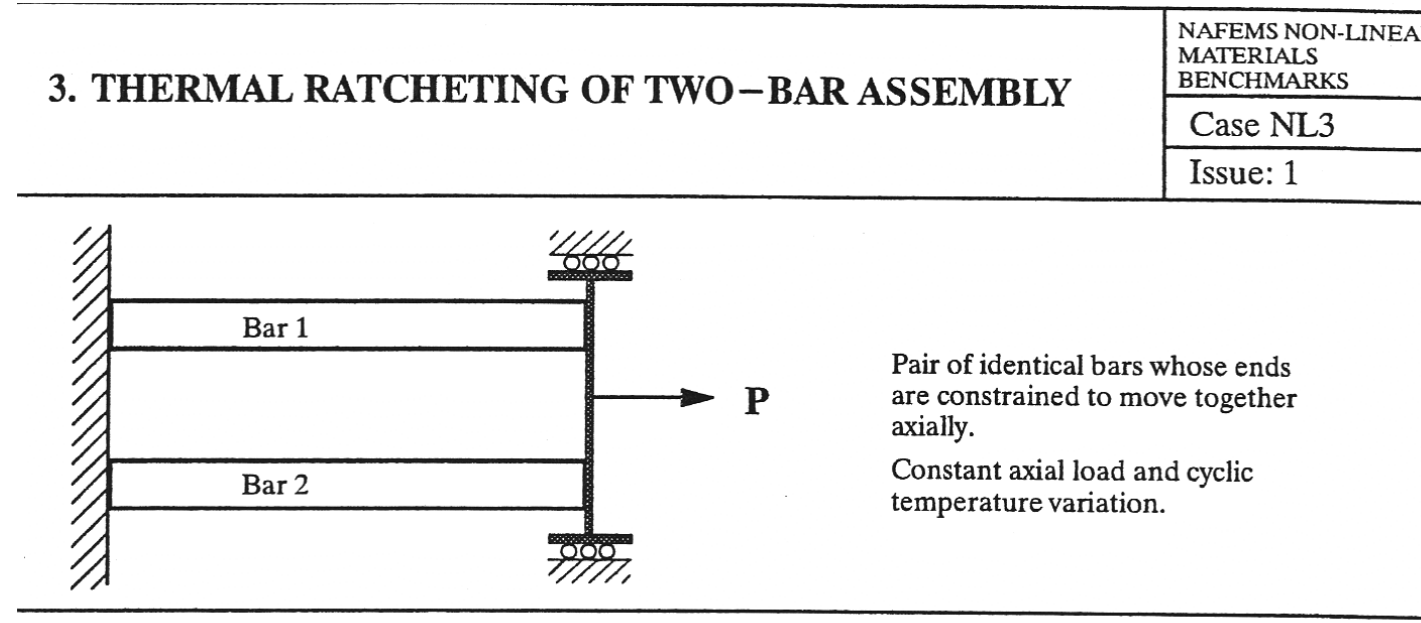

ATTRIBUTES:

- Thermal ratcheting (incremental collapse).

- Perfect plasticity (no hardening).

- '1-dimensional' stress field (discrete values).

\section{MATERIAL / GEOMETRIC PROPERTIES:}

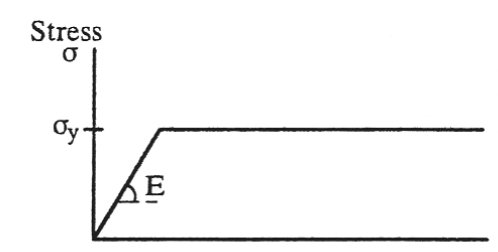

Mechanical Strain $\varepsilon-\alpha \mathrm{T}$

Modulus of elasticity, $\mathrm{E}$

Yield stress, $\sigma_{\mathrm{y}}$

Coefficient of expansion, $\alpha$

Cross-sectional area, A $\underline{\text { Bar 1 }}$ Bar 2 -100

\section{LOAD HISTORY:}

Temperature

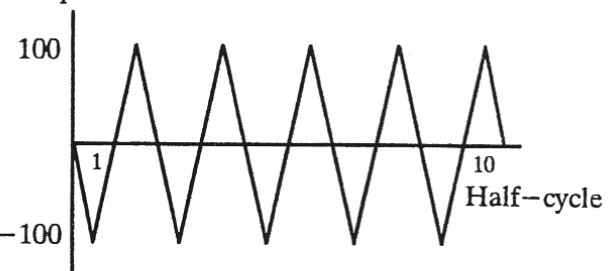

Applied temperature, $\quad$ Bar 1: \pm 100 . Bar 2: 0. Applied mechanical load:

\section{REFERENCE SOLUTION: (analytical)}

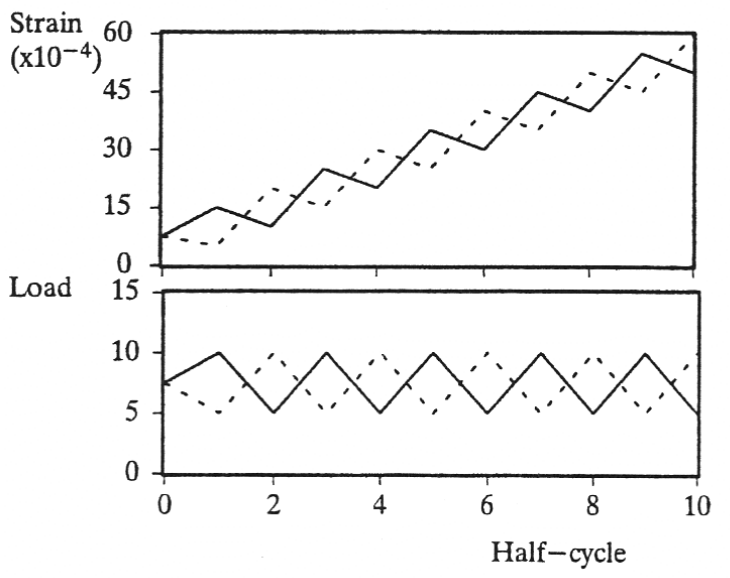

$$
\begin{array}{crrrr}
\text { Half- } & \multicolumn{2}{c}{\text { Axial load }} & \multicolumn{2}{c}{\text { Mechanical strain }\left(x 10^{-4}\right)} \\
\text { cycle } & \text { Bar 1 } & \multicolumn{1}{c}{\text { Bar 2 }} & \multicolumn{1}{c}{\text { Bar 1 }} & \text { Bar 2 } \\
0 & 7.500 & 7.500 & 7.500 & 7.500 \\
1 & 10.000 & 5.000 & 15.000 & 5.000 \\
2 & 5.000 & 10.000 & 10.000 & 20.000 \\
3 & 10.000 & 5.000 & 25.000 & 15.000 \\
4 & 5.000 & 10.000 & 20.000 & 30.000 \\
5 & 10.000 & 5.000 & 35.000 & 25.000 \\
6 & 5.000 & 10.000 & 30.000 & 40.000 \\
7 & 10.000 & 5.000 & 45.000 & 35.000 \\
8 & 5.000 & 10.000 & 40.000 & 50.000 \\
9 & 10.000 & 5.000 & 55.000 & 45.000 \\
10 & 5.000 & 10.000 & 50.000 & 60.000
\end{array}
$$

Note: Total strain equals mechanical strain in bar 2. 
NAFEMS definition for Benchmark NL2A

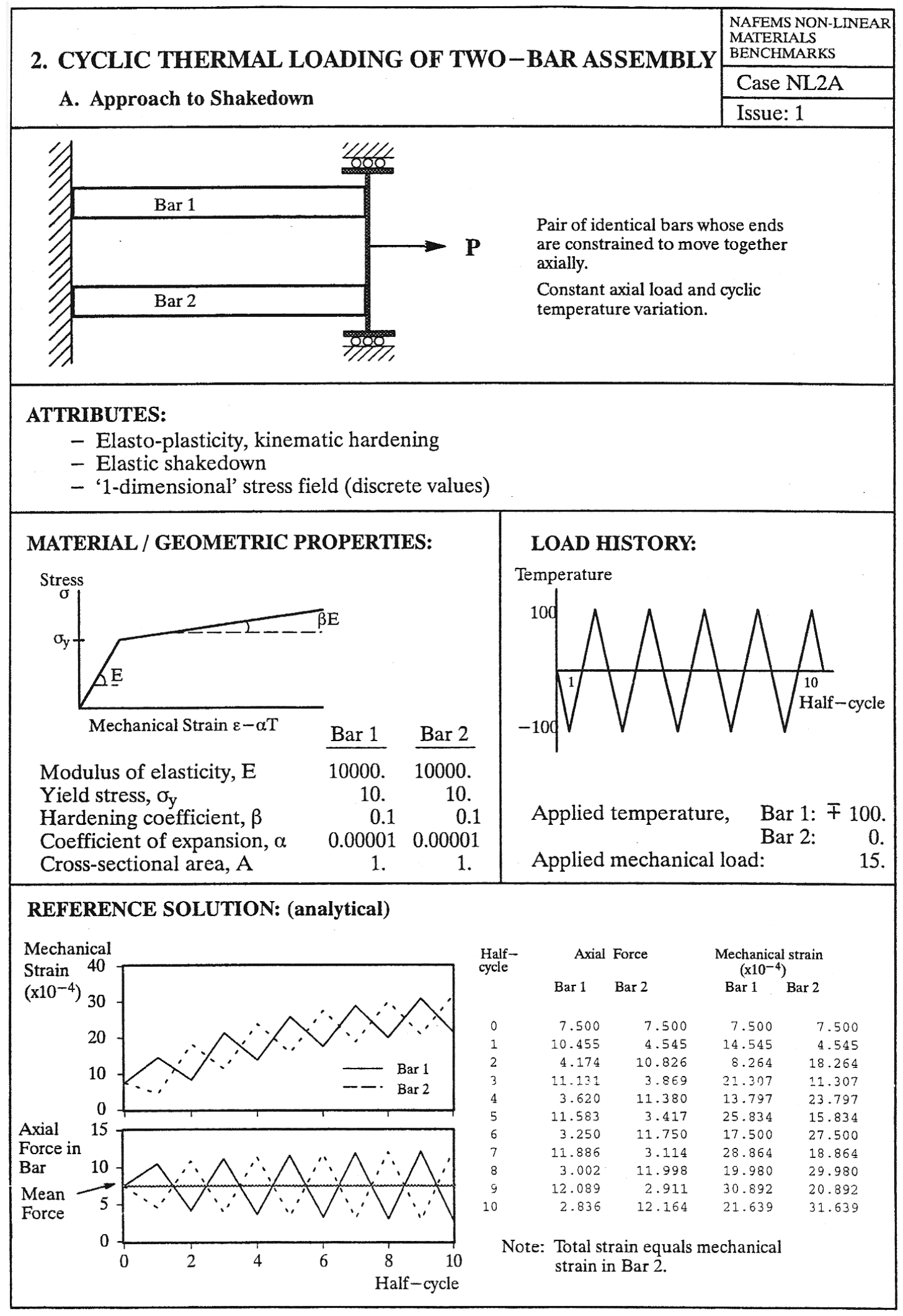




\section{Appendix A}

Detailed response data for problem NL3.

\begin{tabular}{|c|c|c|c|c|}
\cline { 2 - 5 } \multicolumn{1}{c|}{} & \multicolumn{4}{c|}{ Mechanical Strain } \\
\hline half-cycle & Reference $\left(\mathbf{1 0}^{-4}\right)$ & NIKE3D $\left(\mathbf{1 0}^{-4}\right)$ & error & \% error \\
\hline 0 & 7.50 & 7.50 & $6.50 \mathrm{E}-08$ & 0.0087 \\
\hline 1 & 15.00 & 15.00 & $2.02 \mathrm{E}-07$ & 0.0135 \\
\hline 2 & 10.00 & 10.00 & $1.45 \mathrm{E}-07$ & 0.0145 \\
\hline 3 & 25.00 & 24.99 & $8.24 \mathrm{E}-07$ & 0.0330 \\
\hline 4 & 20.00 & 19.99 & $1.17 \mathrm{E}-06$ & 0.0585 \\
\hline 5 & 35.00 & 34.99 & $1.37 \mathrm{E}-06$ & 0.0392 \\
\hline 6 & 30.00 & 29.98 & $1.72 \mathrm{E}-06$ & 0.0573 \\
\hline 7 & 45.00 & 44.98 & $1.92 \mathrm{E}-06$ & 0.0427 \\
\hline 8 & 40.00 & 39.98 & $2.27 \mathrm{E}-06$ & 0.0568 \\
\hline 9 & 55.00 & 54.98 & $2.47 \mathrm{E}-06$ & 0.0449 \\
\hline 10 & 50.00 & 49.97 & $2.82 \mathrm{E}-06$ & 0.0564 \\
\hline
\end{tabular}

Table A1 - Mechanical strain in Bar 1 for problem NL3.

\begin{tabular}{|c|c|c|c|c|}
\cline { 2 - 5 } \multicolumn{1}{c|}{} & \multicolumn{4}{c|}{ Mechanical Strain } \\
\hline half-cycle & Reference $\left(\mathbf{1 0 ^ { - 4 }}\right)$ & NIKE3D $\left(\mathbf{1 0}^{-4}\right)$ & error & \% error \\
\hline 0 & 7.50 & 7.50 & $6.50 \mathrm{E}-08$ & 0.0087 \\
\hline 1 & 5.00 & 5.00 & $2.02 \mathrm{E}-07$ & 0.0404 \\
\hline 2 & 20.00 & 20.00 & $1.45 \mathrm{E}-07$ & 0.0073 \\
\hline 3 & 15.00 & 14.99 & $8.24 \mathrm{E}-07$ & 0.0549 \\
\hline 4 & 30.00 & 29.99 & $1.17 \mathrm{E}-06$ & 0.0390 \\
\hline 5 & 25.00 & 24.99 & $1.37 \mathrm{E}-06$ & 0.0549 \\
\hline 6 & 40.00 & 39.98 & $1.72 \mathrm{E}-06$ & 0.0430 \\
\hline 7 & 35.00 & 34.98 & $1.92 \mathrm{E}-06$ & 0.0549 \\
\hline 8 & 50.00 & 49.98 & $2.27 \mathrm{E}-06$ & 0.0454 \\
\hline 9 & 45.00 & 44.98 & $2.47 \mathrm{E}-06$ & 0.0549 \\
\hline 10 & 60.00 & 59.97 & $2.82 \mathrm{E}-06$ & 0.0470 \\
\hline
\end{tabular}

Table A2 - Mechanical strain in Bar 2 for problem NL3. 


\begin{tabular}{|c|r|r|r|c|}
\cline { 2 - 5 } \multicolumn{1}{c|}{} & \multicolumn{4}{c|}{ Axial Load } \\
\hline half-cycle & Reference & NIKE3D & error & \% error \\
\hline 0 & 7.500 & 7.500 & $0.00 \mathrm{E}+00$ & 0.0000 \\
\hline 1 & 10.000 & 10.000 & $2.00 \mathrm{E}-04$ & 0.0020 \\
\hline 2 & 5.000 & 4.996 & $4.28 \mathrm{E}-03$ & 0.0856 \\
\hline 3 & 10.000 & 10.000 & $4.10 \mathrm{E}-04$ & 0.0041 \\
\hline 4 & 5.000 & 4.996 & $4.28 \mathrm{E}-03$ & 0.0856 \\
\hline 5 & 10.000 & 10.000 & $4.10 \mathrm{E}-04$ & 0.0041 \\
\hline 6 & 5.000 & 4.996 & $4.28 \mathrm{E}-03$ & 0.0856 \\
\hline 7 & 10.000 & 10.000 & $4.10 \mathrm{E}-04$ & 0.0041 \\
\hline 8 & 5.000 & 4.996 & $4.28 \mathrm{E}-03$ & 0.0856 \\
\hline 9 & 10.000 & 10.000 & $4.10 \mathrm{E}-04$ & 0.0041 \\
\hline 10 & 5.000 & 4.996 & $4.28 \mathrm{E}-03$ & 0.0856 \\
\hline
\end{tabular}

Table A3 - Axial load in Bar 1 for problem NL3.

\begin{tabular}{|c|c|r|c|c|}
\cline { 2 - 5 } \multicolumn{1}{c|}{} & \multicolumn{4}{c|}{ Axial Load } \\
\hline half-cycle & Reference & NIKE3D & error & \% error \\
\hline 0 & 7.500 & 7.500 & $0.00 \mathrm{E}+00$ & 0.0000 \\
\hline 1 & 5.000 & 4.999 & $6.07 \mathrm{E}-04$ & 0.0001 \\
\hline 2 & 10.000 & 10.001 & $1.43 \mathrm{E}-03$ & 0.0001 \\
\hline 3 & 5.000 & 4.999 & $1.22 \mathrm{E}-03$ & 0.0002 \\
\hline 4 & 10.000 & 10.001 & $1.43 \mathrm{E}-03$ & 0.0001 \\
\hline 5 & 5.000 & 4.999 & $1.22 \mathrm{E}-03$ & 0.0002 \\
\hline 6 & 10.000 & 10.001 & $1.43 \mathrm{E}-03$ & 0.0001 \\
\hline 7 & 5.000 & 4.999 & $1.22 \mathrm{E}-03$ & 0.0002 \\
\hline 8 & 10.000 & 10.001 & $1.43 \mathrm{E}-03$ & 0.0001 \\
\hline 9 & 5.000 & 4.999 & $1.22 \mathrm{E}-03$ & 0.0002 \\
\hline 10 & 10.000 & 10.001 & $1.43 \mathrm{E}-03$ & 0.0001 \\
\hline
\end{tabular}

Table A4 - Axial load in Bar 2 for problem NL3. 


\section{Appendix B}

Detailed response data for problem NL2A with original model. We use the label "difference" rather than "error" to acknowledge that the results cannot be expected to match due to the distinction between the kinematic hardening of the Reference and the isotropic hardening of NIKE3D's material model 4.

\begin{tabular}{|c|c|c|c|c|}
\cline { 2 - 5 } \multicolumn{1}{c|}{} & \multicolumn{4}{c|}{ Mechanical Strain } \\
\hline half-cycle & Reference $\left(\mathbf{1 0} \mathbf{-}^{-4}\right)$ & NIKE3D $\left(\mathbf{1 0}^{\mathbf{- 4}}\right)$ & difference & \% difference \\
\hline 0 & 7.500 & 7.501 & $6.50 \mathrm{E}-08$ & 0.01 \\
\hline 1 & 14.545 & 14.582 & $3.74 \mathrm{E}-06$ & 0.26 \\
\hline 2 & 8.264 & 8.401 & $1.37 \mathrm{E}-05$ & 1.66 \\
\hline 3 & 21.307 & 21.578 & $2.71 \mathrm{E}-05$ & 1.27 \\
\hline 4 & 13.797 & 14.228 & $4.31 \mathrm{E}-05$ & 3.12 \\
\hline 5 & 25.834 & 26.437 & $6.03 \mathrm{E}-05$ & 2.33 \\
\hline 6 & 17.500 & 18.276 & $7.76 \mathrm{E}-05$ & 4.44 \\
\hline 7 & 28.864 & 29.808 & $9.44 \mathrm{E}-05$ & 3.27 \\
\hline 8 & 19.980 & 21.080 & $1.10 \mathrm{E}-04$ & 5.51 \\
\hline 9 & 30.892 & 32.149 & $1.26 \mathrm{E}-04$ & 4.07 \\
\hline 10 & 21.639 & 23.035 & $1.40 \mathrm{E}-04$ & 6.45 \\
\hline
\end{tabular}

Table B1 - Mechanical strain in Bar 1 for problem NL2A.

\begin{tabular}{|c|c|c|c|c|}
\cline { 2 - 5 } \multicolumn{1}{c|}{} & \multicolumn{4}{c|}{ Mechanical Strain } \\
\hline half-cycle & Reference $\left(\mathbf{1 0}^{-4}\right)$ & NIKE3D $\left(\mathbf{1 0}^{-4}\right)$ & difference & \% difference \\
\hline 0 & 7.500 & 7.501 & $6.50 \mathrm{E}-08$ & 0.01 \\
\hline 1 & 4.545 & 4.582 & $3.74 \mathrm{E}-06$ & 0.82 \\
\hline 2 & 18.264 & 18.401 & $1.37 \mathrm{E}-05$ & 0.75 \\
\hline 3 & 11.307 & 11.578 & $2.71 \mathrm{E}-05$ & 2.39 \\
\hline 4 & 23.797 & 24.228 & $4.31 \mathrm{E}-05$ & 1.81 \\
\hline 5 & 15.834 & 16.437 & $6.03 \mathrm{E}-05$ & 3.81 \\
\hline 6 & 27.500 & 28.276 & $7.76 \mathrm{E}-05$ & 2.82 \\
\hline 7 & 18.864 & 19.808 & $9.44 \mathrm{E}-05$ & 5.00 \\
\hline 8 & 29.980 & 31.080 & $1.10 \mathrm{E}-04$ & 3.67 \\
\hline 9 & 20.892 & 22.149 & $1.26 \mathrm{E}-04$ & 6.02 \\
\hline 10 & 31.639 & 33.035 & $1.40 \mathrm{E}-04$ & 4.41 \\
\hline
\end{tabular}

Table B2 - Mechanical strain in Bar 2 for problem NL2A. 


\begin{tabular}{|c|c|r|r|c|}
\cline { 2 - 5 } \multicolumn{1}{c|}{} & \multicolumn{4}{c|}{ Axial load } \\
\hline half-cycle & Reference & NIKE3D & difference & $\%$ difference \\
\hline 0 & 7.500 & 7.500 & $0.00 \mathrm{E}+00$ & 0.00 \\
\hline 1 & 10.455 & 10.417 & $3.81 \mathrm{E}-02$ & 0.36 \\
\hline 2 & 4.174 & 4.234 & $5.98 \mathrm{E}-02$ & 1.43 \\
\hline 3 & 11.131 & 11.053 & $7.76 \mathrm{E}-02$ & 0.70 \\
\hline 4 & 3.620 & 3.699 & $7.89 \mathrm{E}-02$ & 2.18 \\
\hline 5 & 11.583 & 11.495 & $8.77 \mathrm{E}-02$ & 0.76 \\
\hline 6 & 3.250 & 3.334 & $8.42 \mathrm{E}-02$ & 2.59 \\
\hline 7 & 11.886 & 11.802 & $8.37 \mathrm{E}-02$ & 0.70 \\
\hline 8 & 3.002 & 3.078 & $7.60 \mathrm{E}-02$ & 2.53 \\
\hline 9 & 12.089 & 12.015 & $7.39 \mathrm{E}-02$ & 0.61 \\
\hline 10 & 2.836 & 2.901 & $6.48 \mathrm{E}-02$ & 2.29 \\
\hline
\end{tabular}

Table B3 - Axial load in Bar 1 for problem NL2A.

\begin{tabular}{|c|c|c|c|c|}
\cline { 2 - 5 } \multicolumn{1}{c|}{} & \multicolumn{4}{c|}{ Axial load } \\
\hline half-cycle & Reference & NIKE3D & difference & $\%$ difference \\
\hline 0 & 7.500 & 7.500 & $0.00 \mathrm{E}+00$ & 0.00 \\
\hline 1 & 4.545 & 4.582 & $3.74 \mathrm{E}-02$ & 0.82 \\
\hline 2 & 10.826 & 10.764 & $6.16 \mathrm{E}-02$ & 0.57 \\
\hline 3 & 3.869 & 3.945 & $7.65 \mathrm{E}-02$ & 1.98 \\
\hline 4 & 11.380 & 11.296 & $8.41 \mathrm{E}-02$ & 0.74 \\
\hline 5 & 3.417 & 3.502 & $8.52 \mathrm{E}-02$ & 2.49 \\
\hline 6 & 11.750 & 11.663 & $8.72 \mathrm{E}-02$ & 0.74 \\
\hline 7 & 3.114 & 3.194 & $8.03 \mathrm{E}-02$ & 2.58 \\
\hline 8 & 11.998 & 11.918 & $7.96 \mathrm{E}-02$ & 0.66 \\
\hline 9 & 2.911 & 2.981 & $7.03 \mathrm{E}-02$ & 2.41 \\
\hline 10 & 12.164 & 12.096 & $6.83 \mathrm{E}-02$ & 0.56 \\
\hline
\end{tabular}

Table B4 - Axial load in Bar 2 for problem NL2A. 


\section{Appendix C}

Detailed response data for problem NL2A with revised NIKE3D model.

\begin{tabular}{|c|c|c|c|c|}
\cline { 2 - 5 } \multicolumn{1}{c|}{} & \multicolumn{4}{c|}{ Mechanical Strain } \\
\hline half-cycle & Reference $\left(\mathbf{1 0}^{-4}\right)$ & NIKE3D $\left(\mathbf{1 0} \mathbf{H}^{-4}\right)$ & error & \% error \\
\hline 0 & 7.500 & 7.501 & $6.48 \mathrm{E}-08$ & 0.009 \\
\hline 1 & 14.545 & 14.539 & $-6.24 \mathrm{E}-07$ & -0.043 \\
\hline 2 & 8.264 & 8.259 & $-5.18 \mathrm{E}-07$ & -0.063 \\
\hline 3 & 21.307 & 21.315 & $7.62 \mathrm{E}-07$ & 0.036 \\
\hline 4 & 13.797 & 13.804 & $7.44 \mathrm{E}-07$ & 0.054 \\
\hline 5 & 25.834 & 25.854 & $2.01 \mathrm{E}-06$ & 0.078 \\
\hline 6 & 17.500 & 17.514 & $1.42 \mathrm{E}-06$ & 0.081 \\
\hline 7 & 28.864 & 28.887 & $2.28 \mathrm{E}-05$ & 0.079 \\
\hline 8 & 19.980 & 19.999 & $1.85 \mathrm{E}-04$ & 0.093 \\
\hline 9 & 30.892 & 30.904 & $1.18 \mathrm{E}-06$ & 0.038 \\
\hline 10 & 21.639 & 21.644 & $4.64 \mathrm{E}-07$ & 0.021 \\
\hline
\end{tabular}

Table C1 - Mechanical strain in Bar 1 for problem NL2A with revised model.

\begin{tabular}{|c|c|c|c|c|}
\cline { 2 - 5 } \multicolumn{1}{c|}{} & \multicolumn{4}{c|}{ Mechanical Strain } \\
\hline half-cycle & Reference $\left(\mathbf{1 0}^{-4}\right)$ & NIKE3D $\left(\mathbf{1 0}^{-4}\right)$ & error & \% error \\
\hline 0 & 7.500 & 7.501 & $6.48 \mathrm{E}-08$ & 0.009 \\
\hline 1 & 4.545 & 4.544 & $-7.42 \mathrm{E}-08$ & -0.016 \\
\hline 2 & 18.264 & 18.268 & $3.63 \mathrm{E}-07$ & 0.020 \\
\hline 3 & 11.307 & 11.311 & $3.58 \mathrm{E}-07$ & 0.032 \\
\hline 4 & 23.797 & 23.804 & $6.71 \mathrm{E}-07$ & 0.028 \\
\hline 5 & 15.834 & 15.841 & $6.53 \mathrm{E}-07$ & 0.041 \\
\hline 6 & 27.500 & 27.518 & $1.83 \mathrm{E}-06$ & 0.066 \\
\hline 7 & 18.864 & 18.878 & $1.40 \mathrm{E}-06$ & 0.074 \\
\hline 8 & 29.980 & 30.003 & $2.26 \mathrm{E}-06$ & 0.075 \\
\hline 9 & 20.892 & 20.914 & $2.21 \mathrm{E}-06$ & 0.106 \\
\hline 10 & 31.639 & 31.676 & $3.73 \mathrm{E}-06$ & 0.118 \\
\hline
\end{tabular}

Table C2 - Mechanical strain in Bar 2 for problem NL2A with revised model. 


\begin{tabular}{|c|r|r|r|c|}
\cline { 2 - 5 } \multicolumn{1}{c|}{} & \multicolumn{4}{c|}{ Axial load } \\
\hline half-cycle & Reference & NIKE3D & error & \% error \\
\hline 0 & 7.500 & 7.500 & $0.00 \mathrm{E}+00$ & 0.000 \\
\hline 1 & 10.455 & 10.454 & $-1.17 \mathrm{E}-03$ & -0.011 \\
\hline 2 & 4.174 & 4.173 & $-8.48 \mathrm{E}-04$ & -0.020 \\
\hline 3 & 11.131 & 11.132 & $7.30 \mathrm{E}-04$ & 0.007 \\
\hline 4 & 3.620 & 3.619 & $-7.08 \mathrm{E}-04$ & -0.020 \\
\hline 5 & 11.583 & 11.585 & $2.15 \mathrm{E}-03$ & 0.019 \\
\hline 6 & 3.250 & 3.248 & $-1.78 \mathrm{E}-03$ & -0.055 \\
\hline 7 & 11.886 & 11.889 & $2.69 \mathrm{E}-03$ & 0.023 \\
\hline 8 & 3.002 & 3.000 & $-2.40 \mathrm{E}-03$ & -0.080 \\
\hline 9 & 12.089 & 12.090 & $1.07 \mathrm{E}-03$ & 0.009 \\
\hline 10 & 2.836 & 2.833 & $-3.19 \mathrm{E}-03$ & -0.113 \\
\hline
\end{tabular}

Table C3 - Axial load in Bar 1 for problem NL2A with revised model.

\begin{tabular}{|c|c|c|c|c|}
\cline { 2 - 5 } \multicolumn{1}{c|}{} & \multicolumn{4}{c|}{ Axial load } \\
\hline half-cycle & Reference & NIKE3D & error & \% error \\
\hline 0 & 7.500 & 7.500 & $0.00 \mathrm{E}+00$ & 0.000 \\
\hline 1 & 4.545 & 4.546 & $1.17 \mathrm{E}-04$ & 0.026 \\
\hline 2 & 10.826 & 10.827 & $8.50 \mathrm{E}-04$ & 0.008 \\
\hline 3 & 3.869 & 3.868 & $-7.32 \mathrm{E}-04$ & -0.019 \\
\hline 4 & 11.380 & 11.381 & $7.10 \mathrm{E}-03$ & 0.006 \\
\hline 5 & 3.417 & 3.415 & $-2.15 \mathrm{E}-03$ & -0.063 \\
\hline 6 & 11.750 & 11.752 & $1.78 \mathrm{E}-03$ & 0.015 \\
\hline 7 & 3.114 & 3.111 & $-2.69 \mathrm{E}-03$ & -0.086 \\
\hline 8 & 11.998 & 12.000 & $2.40 \mathrm{E}-03$ & 0.020 \\
\hline 9 & 2.911 & 2.910 & $-1.07 \mathrm{E}-03$ & -0.037 \\
\hline 10 & 12.164 & 12.167 & $3.19 \mathrm{E}-03$ & 0.026 \\
\hline
\end{tabular}

Table C4 - Axial load in Bar 2 for problem NL2A with revised model. 


\title{
Thermal Ratcheting of Uniform Beam
}

\author{
NAFEMS Benchmark NL4 \\ Ryan Greer and Robert Ferencz \\ July and December 2003
}

\section{Introduction}

A uniform beam is first loaded axially to bring the material to 90 percent of its yield strength. It is then subjected to a cyclic, linear through thickness, temperature gradient. This problem demonstrates cyclic accumulation of thermally-driven plastic strain. NIKE3D solutions for plastic strain and total strain are compared with the analytical results given in the NAFEMS benchmark NL4 summary on page 7.

\section{Definition and Approach}

The problem consists of a beam of indeterminant length, 10 units thick. We write indeterminant length because the response is driven by a through-thickness temperature gradient that is invariant with respect to position along its length, and kinematic boundary conditions preclude any curvature. Thus the mechanical response is identical for any cross-section along the length of the beam. We chose to define the beam as 30 units long and 0.5 units wide. At one end the beam is fixed in $x$ and at the other end the beam is constrained to keep the $x$ displacements equal for all nodes. Along the top surface all $y$ displacements are constrained to preclude any curvature. On one side the lateral $z$ displacements are set to zero to prevent a rigid body translation, but the other face is unconstrained to allow stress-free lateral expansion and contraction.

The beam is subjected to a cyclic temperature load varying linearly through the thickness of the beam, keeping the bottom of the beam at a constant temperature of zero. The temperature field was generated using TOPAZ3D and follows the history shown in the NAFEMS summary. The onset of the temperature variation is delayed to permit the constant mechanical load to first be applied to the non-fixed end.

One mesh was developed in TrueGrid using 8-node linear bricks, each 0.25 by 0.25 by 0.5 units. This mesh has an equal number of nodes through the thickness of the beam as the 20 quadratic elements in the NAFEMS "target solution." All material properties defined in the NAFEMS summary were used in this simulation. The Poisson's ratio is undefined and was assumed to be zero. The beam was modeled with NIKE3D's thermalelastic-plastic Model 4. It should be noted that this model only supports isotropic hardening, whereas benchmark NL4 documents results with kinematic hardening.

Final executions were made with NIKE3D source version 3.4.0 dated September 26, 2003. 


\section{Results}

We first confirm that the different plastic hardening laws can be expected to impact the computed results for this problem. Figure 1 shows histories of the axial stress for elements at the top and bottom of the beam. A half-cycle is defined as the time of each maximum or minimum on the temperature load curve. For example, half-cycle 1 correlates with the first minimum temperature of -400 , half-cycle 2 correlates with the subsequent maximum at a temperature of zero, and so on. The values are the elementaveraged quantities reported by Griz. With 40 elements through the thickness these are reasonable surrogates for the extreme lamina values and most likely the manner in which analysts would view and interpret such data. With isotropic hardening the radius of the yield surface expands uniformly, so upon stress reversal no new yielding can occur until the stress magnitude exceeds its previous extrema. In Figure 1 the negative extrema are always smaller than their positive predecessor, consistent with the fact that the corresponding histories of plastic strain (unshown) are stepped and only show increased plasticity during a positive extrema. In contrast, with kinematic hardening the yield surface remains fixed in radius but shifts its center location in deviatoric space. In the present case we would thus anticipate new yielding whenever the negative stress falls below the previous positive extrema minus 200 (where 200 represents two times the initial yield stress). Clearly that is the situation in this problem starting by half-cycle 5, so we anticipate differences between the NAFEMS kinematic and NIKE3D isotropic results.

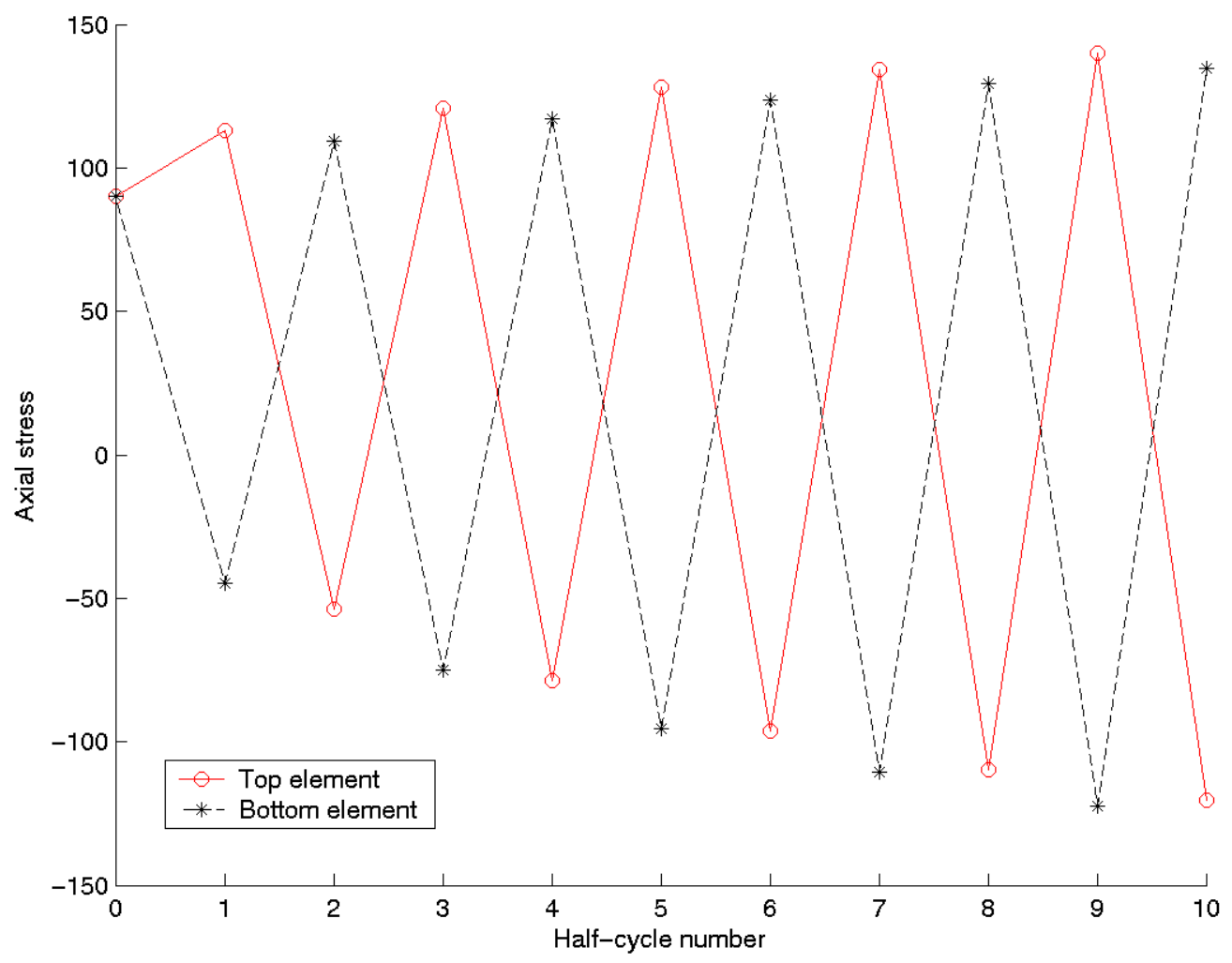

Figure 1 - NIKE3D predictions of axial stress $\sigma_{\mathrm{xx}}$ at the extremes of the beam. 
To provide some insight into the physical response of the problem, Figure 2 plots profiles of plastic strain through the thickness of the beam for six representative half-cycles. During odd-numbered half-cycles the decreasing temperature in the higher lamina induces further tension leading to yielding. The bottom of the beam goes in to compression to equilibrate the constant external load. During the even-numbered cycles the beam returns to a uniform temperature of zero, the now permanently deformed top is thrown into compression and the lower lamina of the beam into tension causing yielding there. The plastic profiles in Figure 2 are in reasonable qualitative agreement with those shown in the NAFEMS documentation. However, for half-cycle 9 NAFEMS shows a slight gradient at the bottom of the beam, and for half-cycle 10 the reference solution shows no gradient near the top of the beam. We believe those features to be in error and will discuss them subsequently.

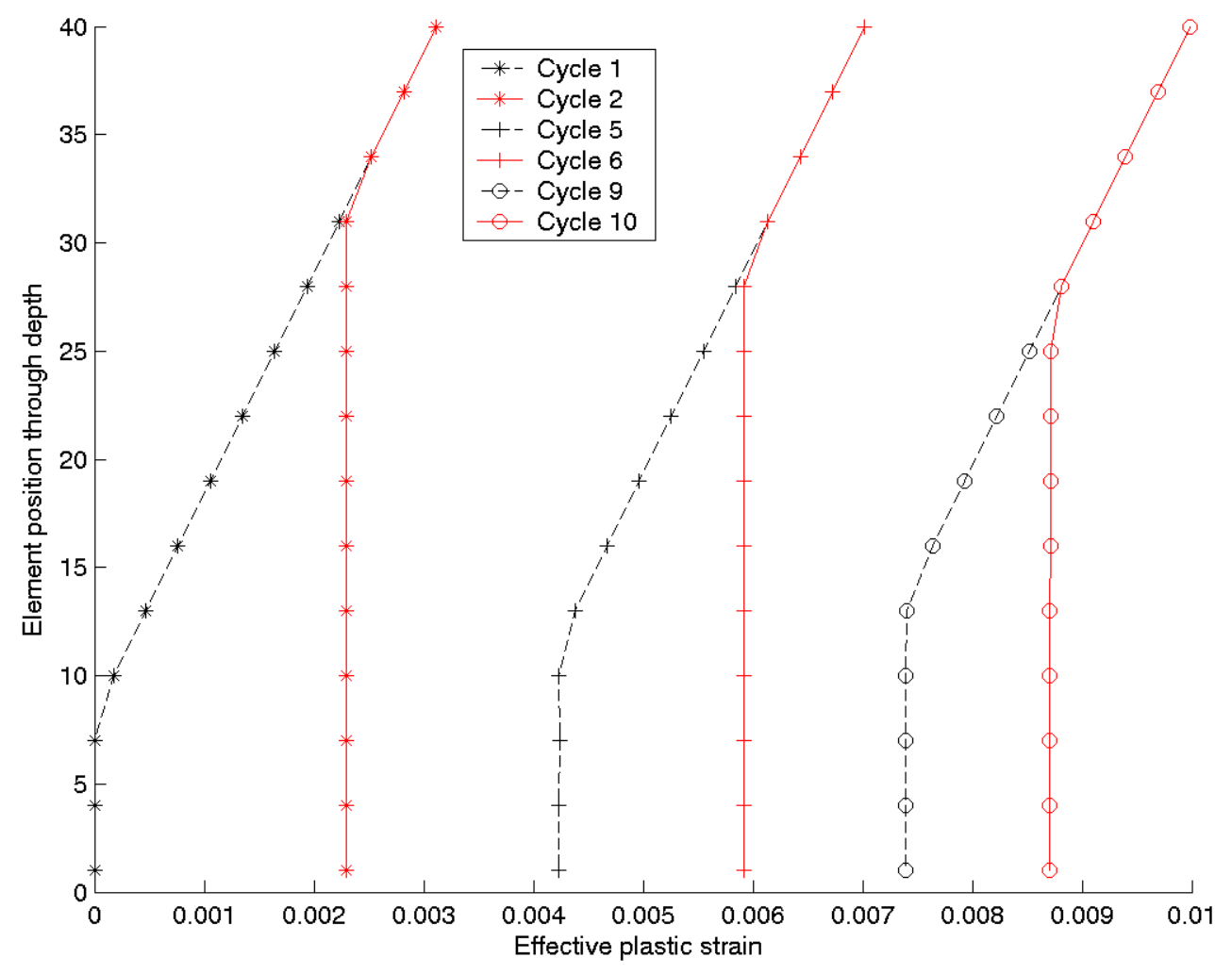

Figure 2 - NIKE3D predictions of plastic strain through height of beam for representative half-cycles of thermal excursions.

Tables A1 and A2 in Appendix A compare the effective plastic strain from the NIKE3D solution to the reference solution. In Figure 3 the first two plots (in red) of the relative difference shows rather peculiar behavior. This can be explained by looking at the NAFEMS reference solution, which is not monotonic with respect to the plastic strain. 
For example, at the top of the beam the plastic strain decreases from 5.2476 to 5.1939 $\left(\times 10^{-3}\right)$ from half-cycles 3 to 4 . The rows highlighted in Tables A1 and A2 indicate instances where the benchmark plastic strain decreases from the value recorded for the previous half-cycle. The benchmark documentation does not offer any explanation as to why this non-physical result was considered acceptable. As no reference is provided, we conclude the benchmark developer himself generated this result. That the reported "target" FEA solution with quadratic membrane elements also displays this lack of monotonicity is strange: perhaps it represents a deficiency of an iterative plane stress implementation of the plasticity routine.

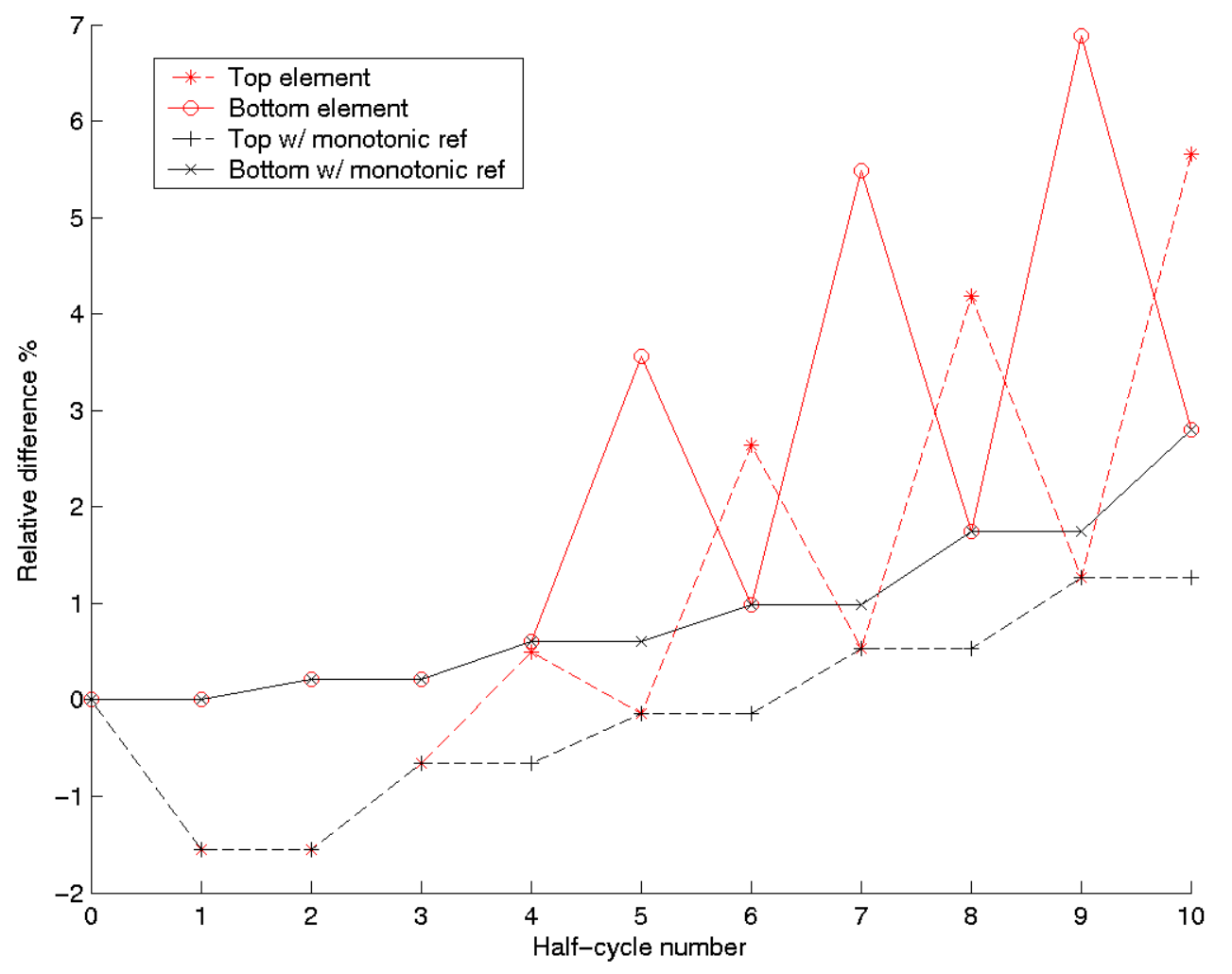

Figure 3 - Relative difference in effective plastic strains between benchmark and NIKE3D.

The latter two plots in Figure 3 are the relative differences between a monotonic NAFEMS benchmark and the NIKE3D results. The monotonic references are constructed by using the previous maximum for the plastic strain whenever the benchmark result decreases. This re-interpretation of the reference seems the best achievable with the information available. This perspective restores a relatively smooth trend to the data, and drops the RMS relative differences from 2.67 to 1.03 percent (top) and 3.37 to 1.36 percent (bottom). 
Of course, for the first plastic excursion at half-cycle 1 we would not expect any difference between kinematic and isotropic hardening. The 1.6 percent difference between the results at the top of the beam can be explained by the difference in sampling locations: top lamina versus element centroid. Using the plastic gradient from the profile in Figure 2, one can extrapolate the NIKE3D result to the beam surface as $3.11 \times 10^{-3} *$ $(40.5-8) /(40-8)=3.16 \times 10^{-3}$, finding it in excellent agreement with the benchmark value.

Table A3 compares results for the total mechanical strain. The NIKE3D total strain was sampled directly from a bottom element using Griz. We note that we believe the reference value for half-cycle 1 contains a typo and should be recorded as $-2.794 \times 10^{-4}$. This is confirmed by comparison with the totally elastic state at the bottom of the beam as well as by adding the thermal strain to the elastic and plastic strains reported for the top surface. Figure 4 plots the relative differences as a function of half-cycle. Agreement for the elastic solution at half-cycle 0 is excellent. With NIKE3D's default nonlinear kinematics the first half-cycle strain is smaller than the benchmarks, but then shows increasingly larger differences for subsequent steps. This echoes the trends seen for the plastic strains in Figure 3 and is concluded to be another manifestation of the difference between kinematic and isotropic hardening. The RMS average relative difference is 1.93 percent. Also plotted are results for NIKE3D's optional linear kinematics. In this case the RMS average relative difference decreases to 1.29 , but there is no compelling reason to prefer this solution. The relatively large differences at half-cycle 1 have no immediate explanation. As there is no gradient in total strain given the kinematic constraints, there are no possible geometric corrections. Perhaps this difference is a result of the meandilatational ("B-bar") formulation of NIKE3D's continuum element. To be consistent with the mean-dilatational strain assumption, the temperature is averaged over the element and a uniform thermal strain computed. This in essence perturbs the applied temperature field from a constant gradient to a series of "stair steps." 


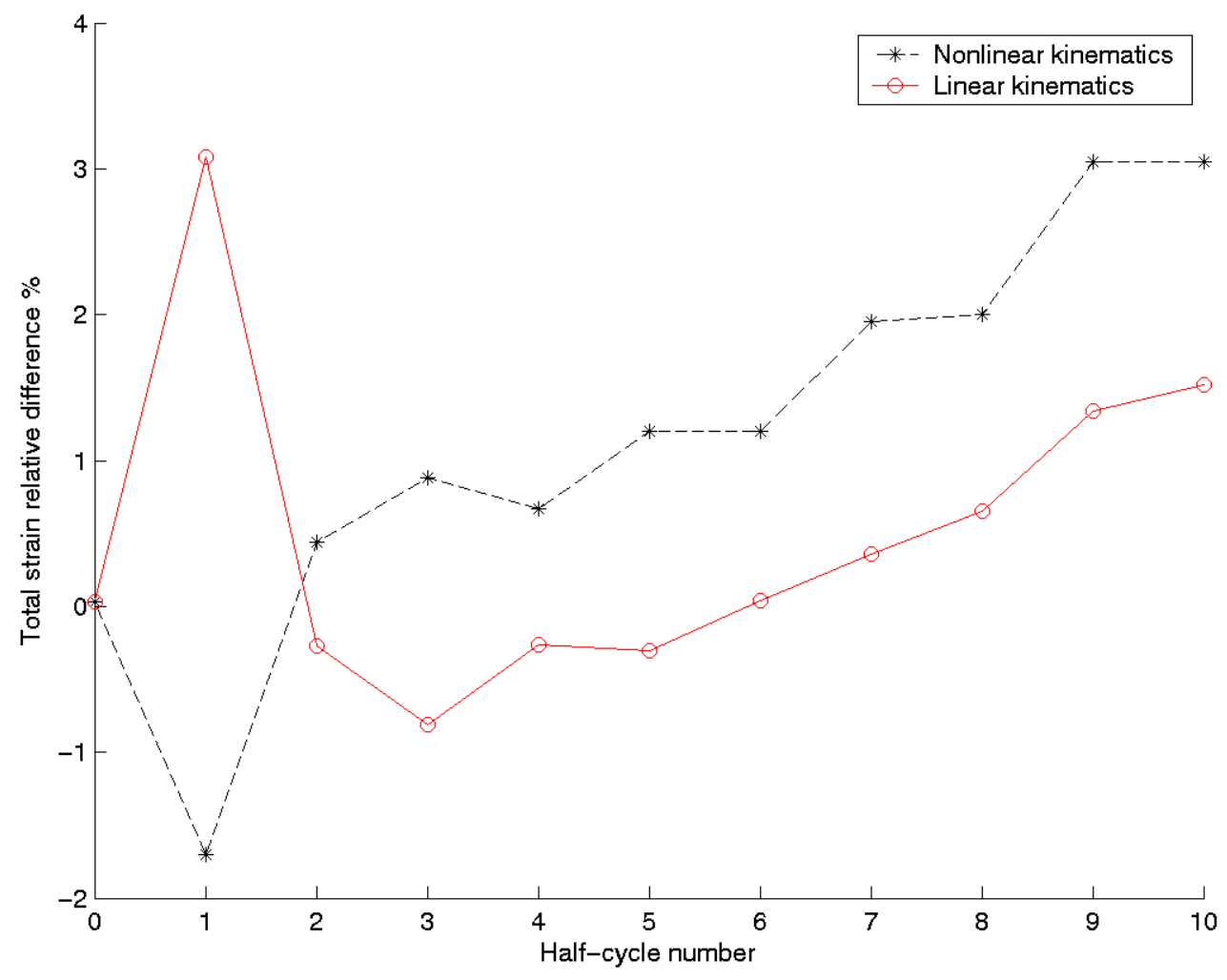

Figure 4 - Relative difference in total strain between benchmark and NIKE3D.

\section{Conclusions/Issues}

The NIKE3D plastic strain solutions are in good agreement with the analytical solution, disregarding the data points in which the reference solution is questionable. The RMS relative difference in plastic strains is order one percent. The total strain however tends to larger peak discrepancies on the order of 3\% relative error. Attempts to create a surrogate model, such as was done for Benchmark NL2A, have not been successful due to the triaxial strain state of the beam and the need to maintain a common nodal topology with the heat conduction model. Nevertheless, the present model is within "working agreement" with the published benchmark and we believe any discrepancy between them can be fundamentally ascribed to the difference in plastic hardening models. Subsequent work might try to confirm this hypothesis by adding a thermal strain term to NIKE3D's material Model 3, which incorporates a kinematic hardening option but is currently isothermal. We only suggest this as a possible "hack" for forensic investigation, not necessarily as an extension of functionality.

\section{References}

D. Linkens, "Selected Benchmarks for Material Non-Linearity," NAFEMS Ref. R0026 Rev. 1, January 1993. 


\section{NAFEMS definition for Benchmark NL4}

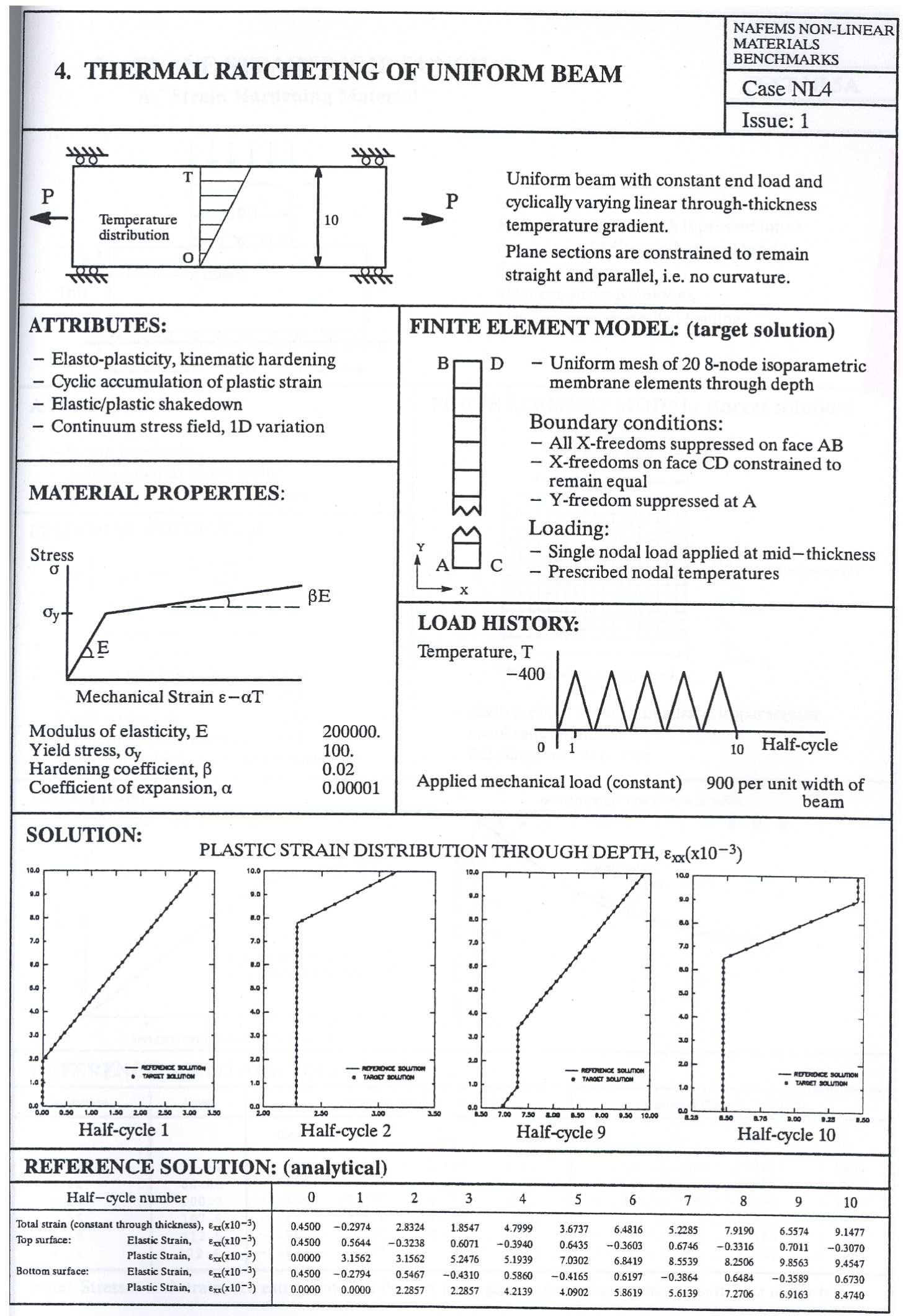




\section{Appendix A}

Detailed response data for problem NL4 using NIKE3D's default nonlinear kinematics.

\begin{tabular}{|c|c|c|c|c|c|}
\cline { 2 - 7 } \multicolumn{1}{c|}{} & \multicolumn{6}{c|}{ Effective Plastic Strain } \\
\hline half-cycle & Analytical & NIKE3D & difference & \% difference & $\begin{array}{c}\text { \% difference } \\
\text { w.r.t monotonic } \\
\text { history }\end{array}$ \\
\hline $\mathbf{0}$ & $0.00 \mathrm{E}+00$ & $0.00 \mathrm{E}+00$ & $0.00 \mathrm{E}+00$ & 0.00 & \\
\hline $\mathbf{1}$ & $3.16 \mathrm{E}-03$ & $3.11 \mathrm{E}-03$ & $-4.91 \mathrm{E}-05$ & -1.55 & \\
\hline $\mathbf{2}$ & $3.16 \mathrm{E}-03$ & $3.11 \mathrm{E}-03$ & $-4.91 \mathrm{E}-05$ & -1.55 & \\
\hline $\mathbf{3}$ & $5.25 \mathrm{E}-03$ & $5.22 \mathrm{E}-03$ & $-3.47 \mathrm{E}-05$ & -0.66 & \\
\hline $\mathbf{4}$ & $5.19 \mathrm{E}-03$ & $5.22 \mathrm{E}-03$ & $2.53 \mathrm{E}-05$ & 0.49 & -0.66 \\
\hline $\mathbf{5}$ & $7.03 \mathrm{E}-03$ & $7.02 \mathrm{E}-03$ & $-9.73 \mathrm{E}-06$ & -0.14 & \\
\hline $\mathbf{6}$ & $6.84 \mathrm{E}-03$ & $7.02 \mathrm{E}-03$ & $1.80 \mathrm{E}-04$ & 2.64 & -0.14 \\
\hline $\mathbf{7}$ & $8.55 \mathrm{E}-03$ & $8.60 \mathrm{E}-03$ & $4.52 \mathrm{E}-05$ & 0.53 & \\
\hline $\mathbf{8}$ & $8.25 \mathrm{E}-03$ & $8.60 \mathrm{E}-03$ & $3.45 \mathrm{E}-04$ & 4.18 & -0.53 \\
\hline $\mathbf{9}$ & $9.86 \mathrm{E}-03$ & $9.99 \mathrm{E}-03$ & $1.25 \mathrm{E}-04$ & 1.27 & \\
\hline $\mathbf{1 0}$ & $9.45 \mathrm{E}-03$ & $9.99 \mathrm{E}-03$ & $5.35 \mathrm{E}-04$ & 5.66 & 1.27 \\
\hline \multicolumn{7}{|c|}{ RMS Average \% difference for cycles 1-10 } & $\mathbf{2 . 6 7}$ & $\mathbf{1 . 0 3}$ \\
\hline
\end{tabular}

Table A1 - Effective plastic strain at the top of the beam with NIKE3D nonlinear kinematics

\begin{tabular}{|c|c|c|c|c|c|}
\hline \multirow[b]{2}{*}{ half-cycle } & \multicolumn{5}{|c|}{ Effective Plastic Strain } \\
\hline & Analytical & NIKE3D & difference & $\%$ difference & $\begin{array}{c}\% \text { difference } \\
\text { w.r.t monotonic } \\
\text { history }\end{array}$ \\
\hline 0 & $0.00 \mathrm{E}+00$ & $0.00 \mathrm{E}+00$ & $0.00 \mathrm{E}+00$ & 0.00 & \\
\hline 1 & $0.00 \mathrm{E}+00$ & $0.00 \mathrm{E}+00$ & $0.00 \mathrm{E}+00$ & 0.00 & \\
\hline 2 & 2.29E-03 & 2.29E-03 & 4.84E-06 & 0.21 & \\
\hline 3 & 2.29E-03 & 2.29E-03 & 4.84E-06 & 0.21 & \\
\hline 4 & $4.21 \mathrm{E}-03$ & 4.24E-03 & 2.57E-05 & 0.61 & \\
\hline 5 & $4.09 E-03$ & $4.24 E-03$ & $1.46 E-04$ & 3.56 & 0.61 \\
\hline 6 & $5.86 \mathrm{E}-03$ & $5.92 E-03$ & $5.81 \mathrm{E}-05$ & 0.99 & \\
\hline 7 & $5.61 E-03$ & 5.92E-03 & $3.08 E-04$ & 5.49 & 0.99 \\
\hline 8 & 7.27E-03 & 7.40E-03 & $1.26 \mathrm{E}-04$ & 1.74 & \\
\hline 9 & $6.92 E-03$ & $7.40 E-03$ & $4.76 E-04$ & 6.88 & 1.74 \\
\hline 10 & 8.47E-03 & $8.71 \mathrm{E}-03$ & $2.37 \mathrm{E}-04$ & 2.80 & \\
\hline \multicolumn{4}{|c|}{ RMS Average \% difference for cycles 1 - 10} & 3.37 & 1.36 \\
\hline
\end{tabular}

Table A2 - Effective plastic strain at the bottom of the beam with NIKE3D nonlinear kinematics 


\begin{tabular}{|c|c|c|c|c|}
\hline & \multicolumn{4}{|c|}{ Total Axial Strain } \\
\hline half-cycle & Analytical & NIKE3D & difference & $\%$ difference \\
\hline 0 & 4.50E-04 & 4.50E-04 & 1.34E-07 & 0.03 \\
\hline 1 & $-2.79 \mathrm{E}-04$ & $-2.75 E-04$ & 4.74E-06 & -1.70 \\
\hline 2 & $2.83 \mathrm{E}-03$ & $2.84 \mathrm{E}-03$ & $1.24 \mathrm{E}-05$ & 0.44 \\
\hline 3 & $1.85 \mathrm{E}-03$ & 1.87E-03 & 1.64E-05 & 0.88 \\
\hline 4 & 4.80E-03 & 4.83E-03 & 3.24E-05 & 0.67 \\
\hline 5 & 3.67E-03 & $3.72 \mathrm{E}-03$ & 4.42E-05 & 1.20 \\
\hline 6 & $6.48 \mathrm{E}-03$ & $6.56 \mathrm{E}-03$ & 7.78E-05 & 1.20 \\
\hline 7 & 5.23E-03 & 5.33E-03 & 1.02E-04 & 1.95 \\
\hline 8 & 7.92E-03 & 8.08E-03 & 1.59E-04 & 2.00 \\
\hline 9 & $6.56 \mathrm{E}-03$ & 6.76E-03 & 2.00E-04 & 3.05 \\
\hline 10 & $9.15 \mathrm{E}-03$ & $9.43 \mathrm{E}-03$ & $2.79 \mathrm{E}-04$ & 3.05 \\
\hline \multicolumn{4}{|c|}{ RMS Average \% difference for cycles 1 - 10} & 1.93 \\
\hline
\end{tabular}

Table A3 - Total axial strain $\varepsilon_{x x}^{\text {tot }}$ (mechanical plus thermal) with NIKE3D nonlinear kinematics 


\section{Appendix B}

Detailed response data for problem NL4 using NIKE3D's optional linear kinematics.

\begin{tabular}{|c|c|c|c|c|c|}
\hline \multirow[b]{2}{*}{ half-cycle } & \multicolumn{5}{|c|}{ Effective Plastic Strain } \\
\hline & Analytical & NIKE3D & difference & $\%$ difference & $\begin{array}{c}\% \text { difference } \\
\text { w.r.t monotonic } \\
\text { history }\end{array}$ \\
\hline 0 & $0.00 \mathrm{E}+00$ & $0.00 \mathrm{E}+00$ & $0.00 \mathrm{E}+00$ & 0.00 & \\
\hline 1 & $3.16 \mathrm{E}-03$ & $3.10 \mathrm{E}-03$ & $-6.18 \mathrm{E}-05$ & -1.96 & \\
\hline 2 & $3.16 \mathrm{E}-03$ & $3.10 \mathrm{E}-03$ & $-6.18 \mathrm{E}-05$ & -1.96 & \\
\hline 3 & $5.25 \mathrm{E}-03$ & 5.19E-03 & $-6.38 \mathrm{E}-05$ & -1.22 & \\
\hline 4 & $5.19 E-03$ & $5.19 E-03$ & $-3.80 E-06$ & -0.07 & -1.22 \\
\hline 5 & 7.03E-03 & 6.97E-03 & $-5.61 \mathrm{E}-05$ & -0.80 & \\
\hline 6 & $6.84 E-03$ & $6.97 E-03$ & $1.34 E-04$ & 1.96 & -0.80 \\
\hline 7 & $8.55 \mathrm{E}-03$ & $8.53 E-03$ & $-2.25 E-05$ & -0.26 & \\
\hline 8 & $8.25 E-03$ & $8.53 E-03$ & $2.77 E-04$ & 3.36 & -0.25 \\
\hline 9 & 9.86E-03 & 9.90E-03 & 3.87E-05 & 0.39 & \\
\hline 10 & $9.45 E-03$ & $9.90 E-03$ & $4.49 E-04$ & 4.75 & 0.39 \\
\hline \multicolumn{4}{|c|}{ RMS Average \% difference for cycles 1 - 10} & 2.30 & 1.17 \\
\hline
\end{tabular}

Table B1 - Effective plastic strain at the top of the beam with NIKE3D linear kinematics

\begin{tabular}{|c|c|c|c|c|c|}
\cline { 2 - 6 } \multicolumn{1}{c|}{} & \multicolumn{5}{c|}{ Effective Plastic Strain } \\
\hline half-cycle & Analytical & NIKE3D & difference & \% difference & $\begin{array}{c}\text { \% difference } \\
\text { w.r.t monotonic } \\
\text { history }\end{array}$ \\
\hline $\mathbf{0}$ & $0.00 \mathrm{E}+00$ & $0.00 \mathrm{E}+00$ & $0.00 \mathrm{E}+00$ & 0.00 & \\
\hline $\mathbf{1}$ & $0.00 \mathrm{E}+00$ & $0.00 \mathrm{E}+00$ & $-1.09 \mathrm{E}-05$ & 0.00 & \\
\hline $\mathbf{2}$ & $2.29 \mathrm{E}-03$ & $2.28 \mathrm{E}-03$ & $-1.09 \mathrm{E}-05$ & -0.48 & \\
\hline $\mathbf{3}$ & $2.29 \mathrm{E}-03$ & $2.28 \mathrm{E}-03$ & $-6.39 \mathrm{E}-06$ & -0.48 & \\
\hline $\mathbf{4}$ & $4.21 \mathrm{E}-03$ & $4.20 \mathrm{E}-03$ & $1.14 \mathrm{E}-04$ & -0.15 & \\
\hline $\mathbf{5}$ & $4.09 \mathrm{E}-03$ & $4.20 \mathrm{E}-03$ & $6.76 \mathrm{E}-06$ & 2.78 & -0.15 \\
\hline $\mathbf{6}$ & $5.86 \mathrm{E}-03$ & $5.87 \mathrm{E}-03$ & $2.57 \mathrm{E}-04$ & 0.12 & \\
\hline $\mathbf{7}$ & $5.61 \mathrm{E}-03$ & $5.87 \mathrm{E}-03$ & $5.44 \mathrm{E}-05$ & 4.58 & 0.12 \\
\hline $\mathbf{8}$ & $7.27 \mathrm{E}-03$ & $7.32 \mathrm{E}-03$ & $4.04 \mathrm{E}-04$ & 0.75 & \\
\hline $\mathbf{9}$ & $6.92 \mathrm{E}-03$ & $7.32 \mathrm{E}-03$ & $1.45 \mathrm{E}-04$ & 5.84 & 0.75 \\
\hline $\mathbf{1 0}$ & $8.47 \mathrm{E}-03$ & $8.61 \mathrm{E}-03$ & $0.00 \mathrm{E}+00$ & 1.71 & \\
\hline \multicolumn{7}{|c|}{ RMS Average \% difference for cycles 1- 10 } & $\mathbf{2 . 7 2}$ & $\mathbf{0 . 7 1}$ \\
\hline
\end{tabular}

Table B2 - Effective plastic strain at the bottom of the beam with NIKE3D linear kinematics 


\begin{tabular}{|c|c|c|c|c|}
\hline \multirow[b]{2}{*}{ half-cycle } & \multicolumn{4}{|c|}{ Total Axial Strain } \\
\hline & Analytical & NIKE3D & difference & $\%$ difference \\
\hline 0 & $4.50 \mathrm{E}-04$ & 4.50E-04 & $1.34 \mathrm{E}-07$ & 0.03 \\
\hline 1 & $-2.79 \mathrm{E}-04$ & $-2.88 \mathrm{E}-04$ & $-8.61 \mathrm{E}-06$ & 3.08 \\
\hline 2 & $2.83 \mathrm{E}-03$ & 2.82E-03 & $-7.62 \mathrm{E}-06$ & -0.27 \\
\hline 3 & 1.85E-03 & $1.84 \mathrm{E}-03$ & $-1.51 \mathrm{E}-05$ & -0.81 \\
\hline 4 & 4.80E-03 & 4.79E-03 & $-1.25 \mathrm{E}-05$ & -0.26 \\
\hline 5 & 3.67E-03 & 3.66E-03 & $-1.11 \mathrm{E}-05$ & -0.30 \\
\hline 6 & $6.48 \mathrm{E}-03$ & $6.48 \mathrm{E}-03$ & $2.43 \mathrm{E}-06$ & 0.04 \\
\hline 7 & 5.23E-03 & $5.25 E-03$ & 1.86E-05 & 0.36 \\
\hline 8 & 7.92E-03 & 7.97E-03 & $5.16 \mathrm{E}-05$ & 0.65 \\
\hline 9 & $6.56 \mathrm{E}-03$ & $6.65 \mathrm{E}-03$ & 8.78E-05 & 1.34 \\
\hline 10 & $9.15 \mathrm{E}-03$ & 9.29E-03 & $1.39 \mathrm{E}-04$ & 1.52 \\
\hline \multicolumn{4}{|c|}{ RMS Average \% difference for cycles 1 - 10} & 1.29 \\
\hline
\end{tabular}

Table B3 - Total axial strain $\varepsilon_{x x}^{\text {tot }}$ (mechanical plus thermal) with NIKE3D linear kinematics 